\title{
Mulinane- and Azorellane-Type Diterpenoids: A Systematic Review of Their Biosynthesis, Chemistry, and Pharmacology
}

\author{
Angel de Jesús Dzul-Beh ${ }^{1,+}{ }^{\mathbb{D}}$, Andrés Humberto Uc-Cachón ${ }^{1,+}{ }^{\mathbb{C}}$, Jorge Bórquez ${ }^{2}$, \\ Luis A. Loyola ${ }^{2}$, Luis Manuel Peña-Rodríguez ${ }^{3} \mathbb{D}$ and Gloria María Molina-Salinas ${ }^{1, *(D)}$ \\ 1 Unidad de Investigación Médica Yucatán, Unidad Médica de Alta Especialidad Hospital de Especialidades \\ 1 Mérida, Yucatán, Instituto Mexicano del Seguro Social, Mérida 97150, Yucatán, Mexico; \\ angeldzulbeh1992@gmail.com (A.d.J.D.-B.); andresuccachon@gmail.com (A.H.U.-C.) \\ 2 Departamento de Química, Facultad de Ciencias Básicas, Universidad de Antofagasta, \\ Antofagasta 02800, Chile; jorge.borquez@uantof.cl (J.B.); aloyola@uantof.cl (L.A.L.) \\ 3 Unidad de Biotecnología, Centro de Investigación Científica de Yucatán, A.C., Mérida 97205, \\ Yucatán, Mexico; lmanuel@cicy.mx \\ * Correspondence: gmolina70@gmail.com; Tel.: +52-(999)-922-5656 (ext. 61677) \\ + Equally contributing authors.
}

Received: 31 August 2020; Accepted: 15 September 2020; Published: 17 September 2020

\begin{abstract}
Mulinane- and azorellane-type diterpenoids have unique tricyclic fused five-, six-, and seven-membered systems and a wide range of biological properties, including antimicrobial, antiprotozoal, spermicidal, gastroprotective, and anti-inflammatory, among others. These secondary metabolites are exclusive constituents of medicinal plants belonging to the Azorella, Laretia, and Mulinum genera. In the last 30 years, more than 95 mulinanes and azorellanes have been reported, 49 of them being natural products, 4 synthetics, and the rest semisynthetic and biotransformed derivatives. This systematic review highlights the biosynthetic origin, the chemistry, and the pharmacological activities of this remarkably interesting group of diterpenoids.
\end{abstract}

Keywords: mulinane; azorellane; diterpenoids; antimycobacterial; antiulcer

\section{Introduction}

For millennia, humankind has relied heavily on nature to provide for its basic needs, and to alleviate a wide spectrum of diseases. It is well documented that plants constitute the basis of traditional medicine systems; fossil records date the human use of plants as medicines to at least the Middle Paleolithic age, some 60,000 year ago [1,2]. In Mesopotamia, the uses of approximately 1000 plant-derived substances were documented around 2600 B.C. [3]. Currently, herbal remedies continue to be used for the treatment of different diseases by a large number of people; it has been reported that between $70 \%$ and $95 \%$ of the population, mainly in developing countries, still use traditional medicine as their primary health care when caring for their health-related needs and concerns [4].

Many plant species have been reported to possess pharmacological activities which are due to their content of natural products, broadly defined as small molecules derived from primary metabolites (e.g. carbohydrates, amino acids, etc.), used by the plant to mediate its interactions with the surrounding environment [5,6]. These natural products are genetically encoded and are produced by secondary metabolic pathways [6]. The four main families of secondary metabolites include polyketides, terpenoids, polyphenols derivatives, and alkaloids, and can be found in the leaves, stems, root, and bark of plants [7]. 
Since the early 20th century, and to date, natural products have received a great deal of attention because of their importance in the development of new pharmaceuticals [7]. It has been reported that between 50 to $70 \%$ of the approved small-molecule drugs that came into market in the period between 1981 to 2014 were derived from natural products, including unaltered natural products, chemically modified derivatives, and synthetic natural mimics derived from a natural-product template or a pharmacophore [8]. In addition, natural products and their derivatives represent more than one-third of all U.S. Federal Drug Administration (FDA)-approved new molecular entities, especially for antibiotic and anticancer molecules [9].

The mulinane and azorellane diterpenoids are a group of structurally-interesting natural products which have been reported to show a wide variety of biological activities including antimicrobial, antiprotozoal, antitumor, anti-inflammatory, and antimycobacterial, among others [10]. While mulinanes have a tricyclic skeleton of fused five-, six-, and seven-membered rings, with an angular substituent at each of the ring junctions, the skeleton of the azorellanes includes a tetracyclic arrangement (Figure 1). Nearly all mulinanes are characterized by having a carboxyl group at the C-20 position and a functionalized seven-member ring. In contrast, in azorellanes C-20 is not functionalized but C-13 is usually oxygenated [11,12].
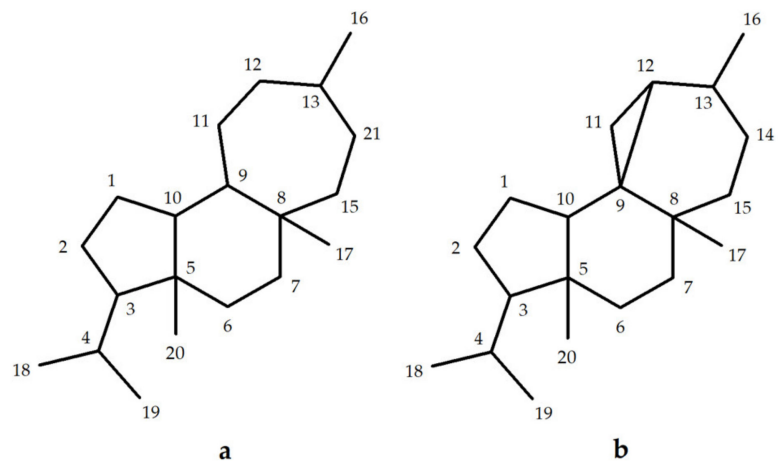

Figure 1. Carbon skeletons of mulinane (a) and azorellane (b) diterpenoids.

These diterpenoids have been reported exclusively from species of the genus Azorella, Laretia and Mulinum (Apiaceae, Umbelliferae) [10], and particularly from Azorella compacta Phil and Mulinum crassifolium Phil. In fact, the analysis of $A$. compacta resin by gas chromatography-mass spectrometry showed that the relative composition was $99 \%$ diterpenoids, where the dominant components were oxygenated diterpenoids [13]. Both species have traditionally been used by native people in South America for their medicinal properties; A. compacta is reportedly used for the treatment of different types of colds, as well as bronchitis, asthma, inflammation, diabetes, skin disorders, toothache, backache, and disorders of the kidney and uterus $[14,15]$, and M. crassifolium is used to treat diabetes, bronchial and intestinal disorders, and stomach problems [15,16].

This review provides an outlook on the biosynthesis, chemistry, and pharmacological properties of mulinane and azorellane diterpenoids.

\section{Literature Search}

A precise literature search was carried out with Google Scholar, Scopus, PubMed, Science Direct, CONRICYT repositories for related findings. The following keywords: Activity + Mulinum + Diterpenoids, Activity + Laretia + Diterpenoids, Activity + Azorella + Diterpenoids, Diterpenoids + Azorella, Diterpenoids + Laretia, Diterpenoids + Mulinum, Diterpenoids + Azorellane, Diterpenoids + Mulinane, Activity + Diterpenoids + Azorellane, Activity + Diterpenoids + Mulinane, were used to find all the relevant literature published on mulinanes and azorellanes, their biosynthesis, sources, pharmacological activities, synthesis, and modifications conferred on their structure. In this research, time interval was not used, all related findings were included. 


\section{Mulinane and Azorellane Biosynthesis}

While it has been suggested that mulinane biogenesis derives from the biogenetic transformation of a labdane derivative [17], a different proposal for the biosynthetic origin of mulinane and azorellane diterpenoids (Figure 2) starts with the cyclization of the C-20 general precursor geranylgeranyl pyrophosphate (GGPP) to produce all trans-GGPP, which is then isomerized to S-geranyllinaloyl pyrophosphate (S-GLPP); an anti-Markovnikov cyclization generates the enantiomeric cation I that, by means of cyclization, yields the bicyclic system II a sigmatropic rearrangement, and leads to the stereoisomeric ion III having angular methyl groups considered the syn precursor of mulinanes and azorellanes. Cyclization of the side chain yields the tricyclic system IV, with an all-trans ring junctions' stereochemistry, that, following a series of 1,2-hydride and methyl shifts, leads to V. The intermediate $\mathrm{V}$ is the true precursor of mulinanes and azorellanes; a 1,2-hydride shift followed by deprotonation yields the mulinane skeleton, while the loss of the allylic proton produces the cyclopropane ring found in azorellanes [11].<smiles>CC(C)=CCCC(=CCCC1(C)CC=C(C)CCC1)CCC(C)=CCCC(C)=CCCC(C)=CCCC(C)=CCCC(C)C</smiles>

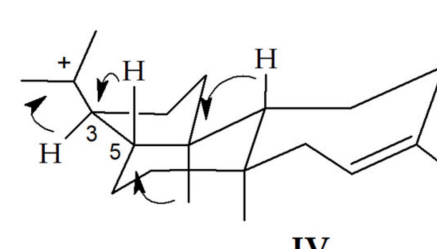

IV

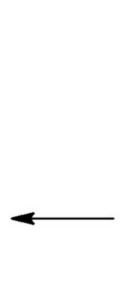

(2)<smiles>C1CCCC1</smiles>
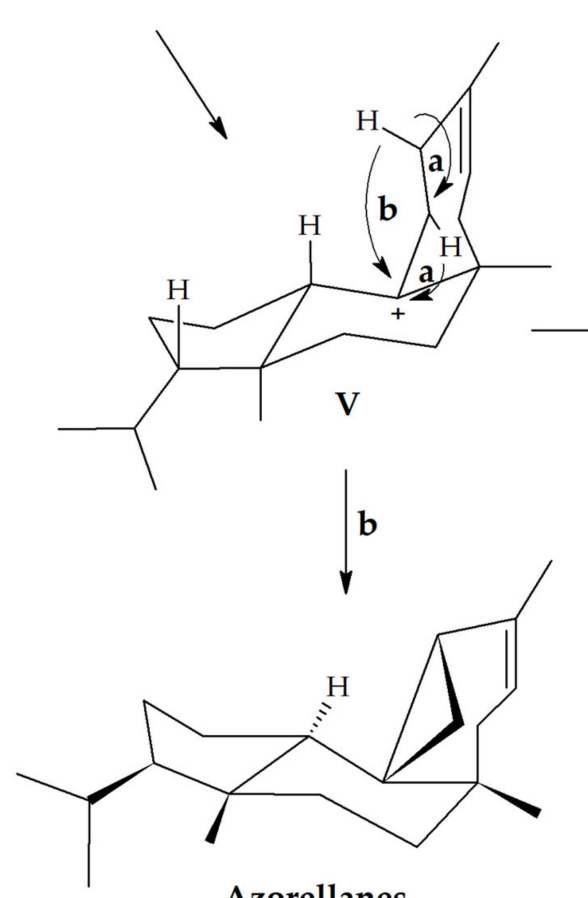

Azorellanes

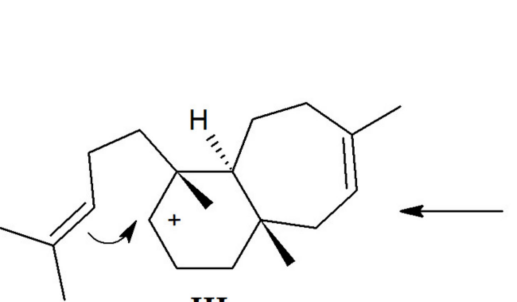

III<smiles>CCCC=C(C)C</smiles><smiles>CCCC(C)=C1C=CC2(C)CC=C(C)CC[C@H]12</smiles>

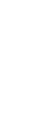

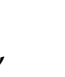




\section{Sources and Chemical Structures of Natural Mulinane and Azorellane Diterpenoids}

Species of the genera Mulinum, Azorella, and Laretia are well-recognized sources of diterpenoids with mulinane and azorellane skeletons. While mulinanes are only present in Mulinum spp., the Azorella and Laretia genera are known to produce secondary metabolites with both mulinane and azorellane skeletons [10]. Azorella spp., Mulinum spp., and Laretia spp. include perennial shrubs, cushions, or mat-forming species that are adapted to cold and windy terrain and are often found at high-elevation habitats, particularly in the Andes mountain range of South America [18]. These species are distributed in southernmost South America and in the Subantarctic islands, as well as south of Australia and New Zealand. In South America, they extend from the Subantarctic region northward through the Patagonian steppes of Argentina and Chile and further north, they are restricted to the Andes Plateau highlands [19].

The first mulinane diterpenoids, mulinic acid (1) and isomulinic acid (2), were reported from M. crassifolium in 1990 [17]; similarly, the first azorellane diterpenoid was azorellanol (9) from A. compacta in 1998 [20]. To date, 37 mulinane and 12 azorellane diterpenoids have been isolated from Azorella spp., Laretia spp., and Mulinum spp. (Table 1, and Figure 3).

Table 1. Mulinane and azorellane diterpenoids isolated from Mulinum spp., Azorella spp., and Laretia spp.

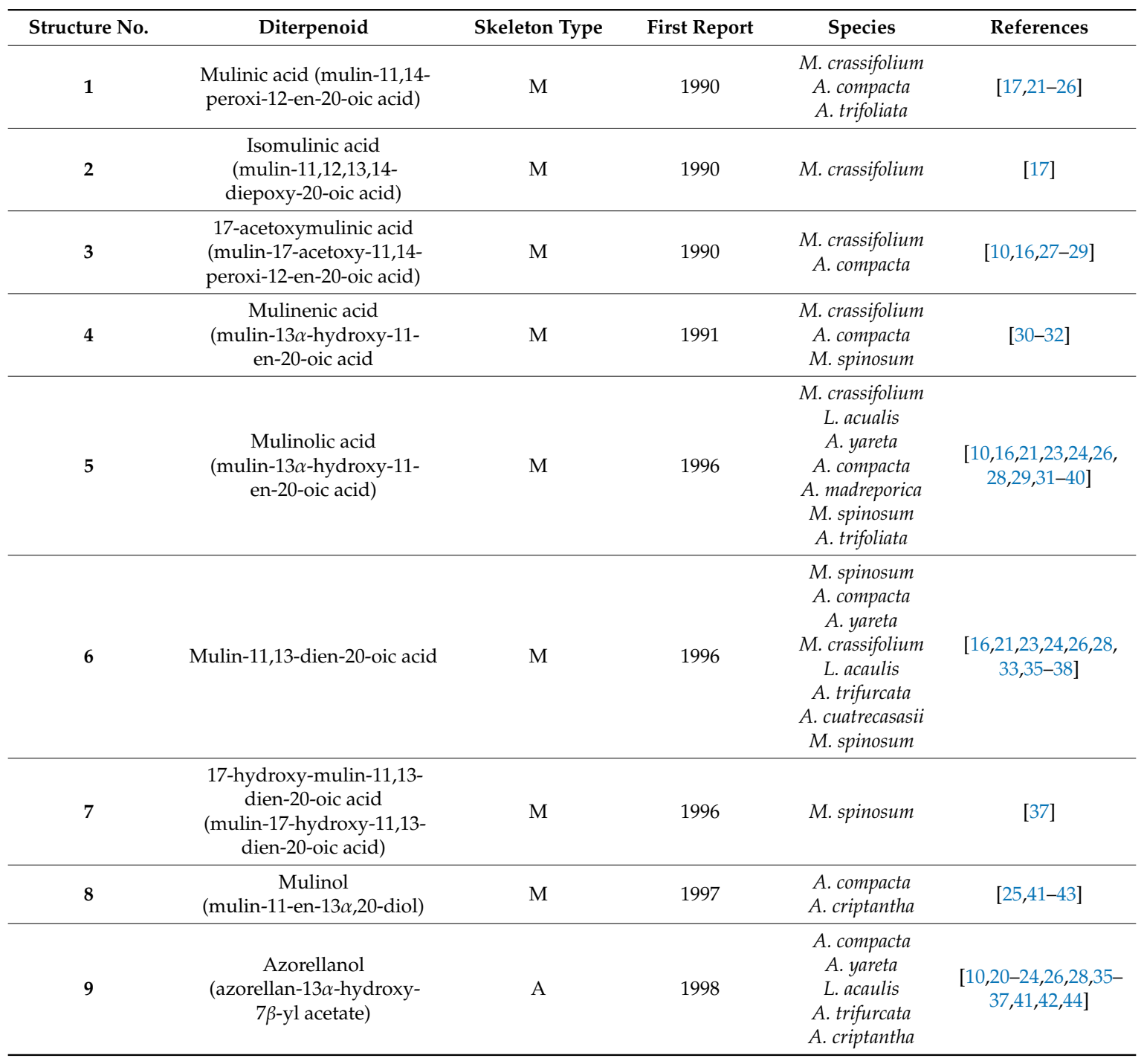


Table 1. Cont.

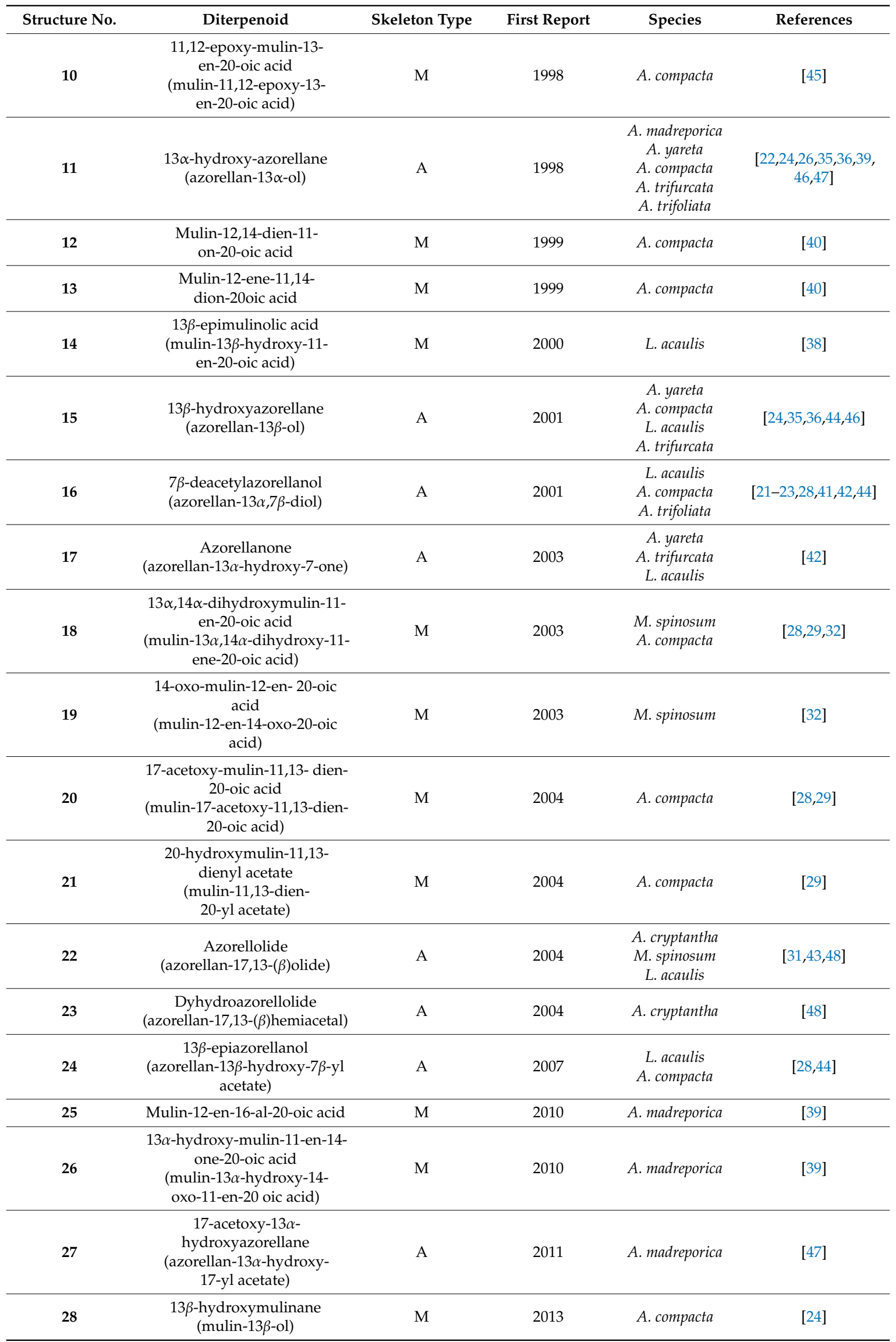


Table 1. Cont.

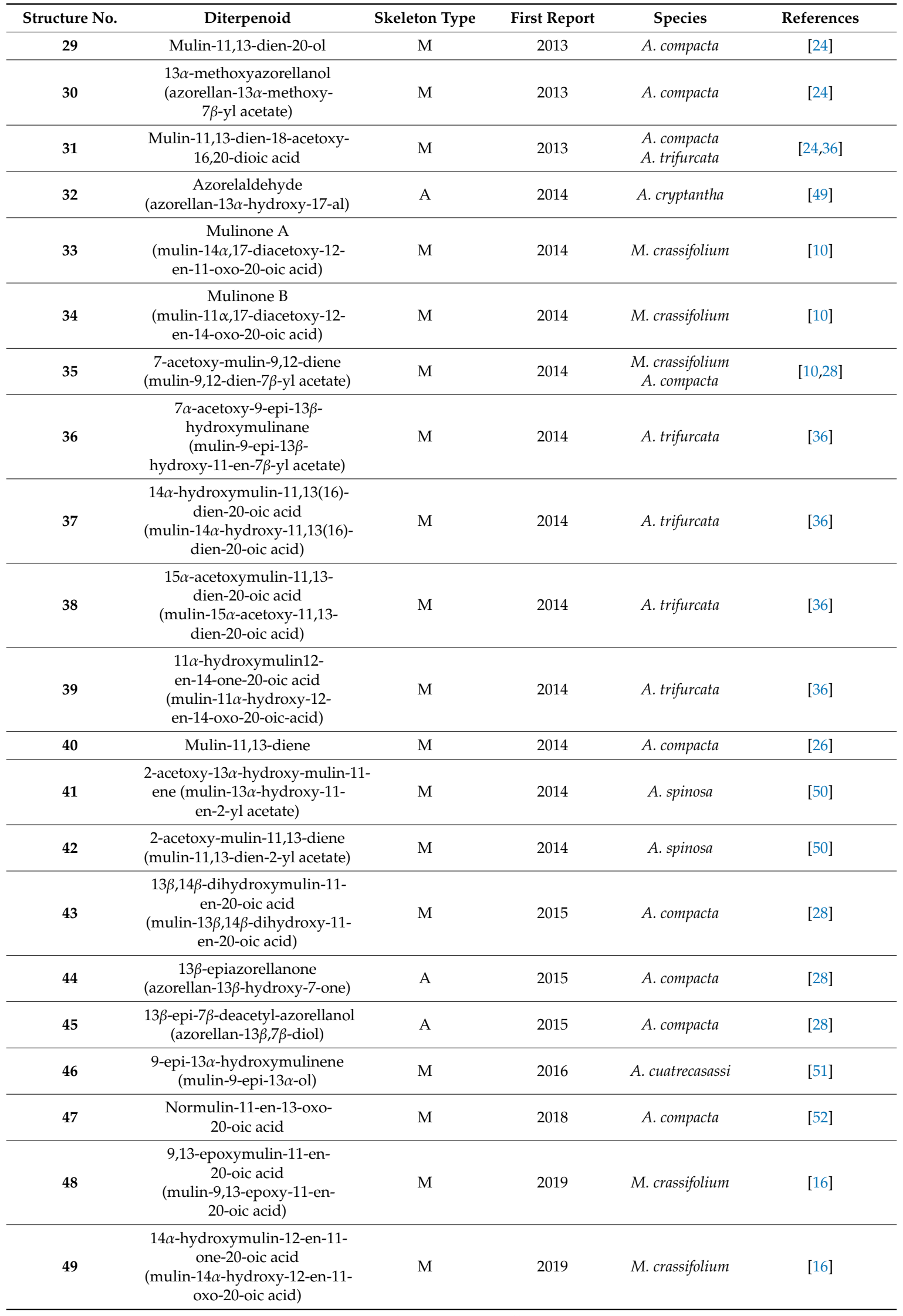



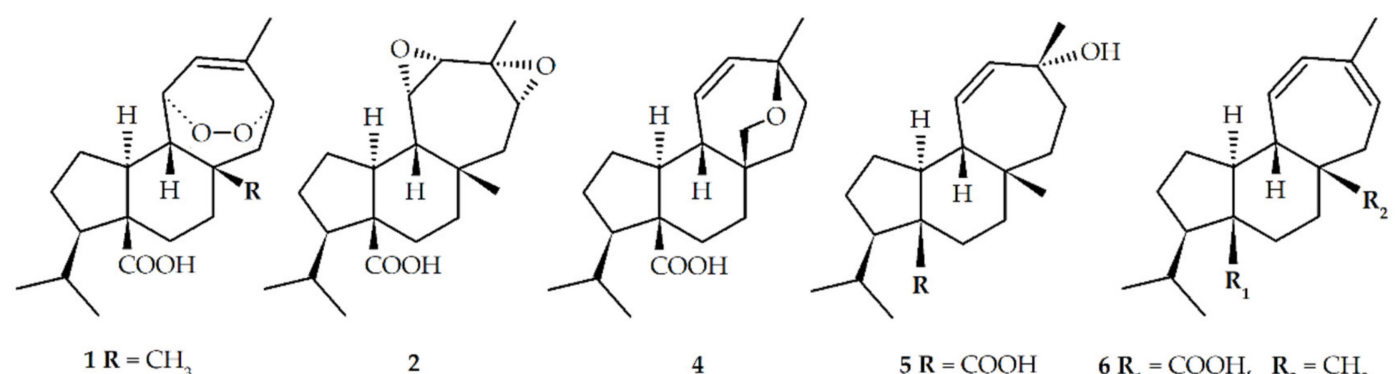

$3 \mathrm{R}=\mathrm{CH}_{2} \mathrm{OAC}$

4

$\mathbf{5} \mathbf{R}=\mathrm{COOH} \quad 6 \mathbf{R}_{1}=\mathrm{COOH}, \quad \mathbf{R}_{2}=\mathrm{CH}_{3}$

$8 \mathrm{R}=\mathrm{CH}_{2} \mathrm{OH} \quad 7 \mathrm{R}_{1}=\mathrm{COOH}, \mathrm{R}_{2}=\mathrm{CH}_{2} \mathrm{OH}$

$20 \mathrm{R}_{1}=\mathrm{COOH}, \quad \mathbf{R}_{2}=\mathrm{CH}_{2} \mathrm{OAC}$

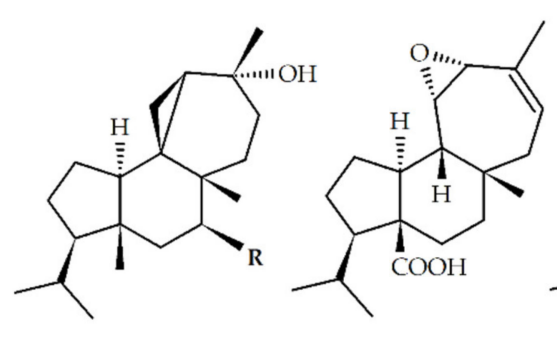

(n)

$21 \mathrm{R}_{1}=\mathrm{CH}_{2} \mathrm{OAc}, \mathrm{R}_{2}=\mathrm{CI}_{3}$

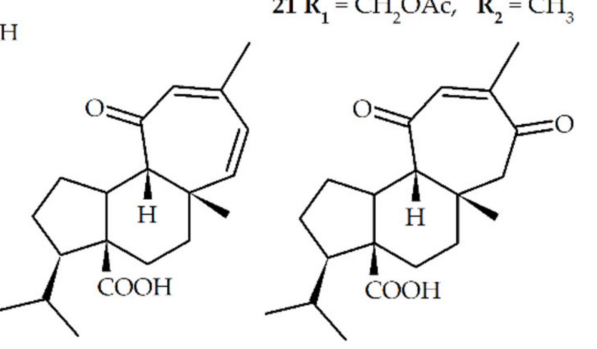

12

13

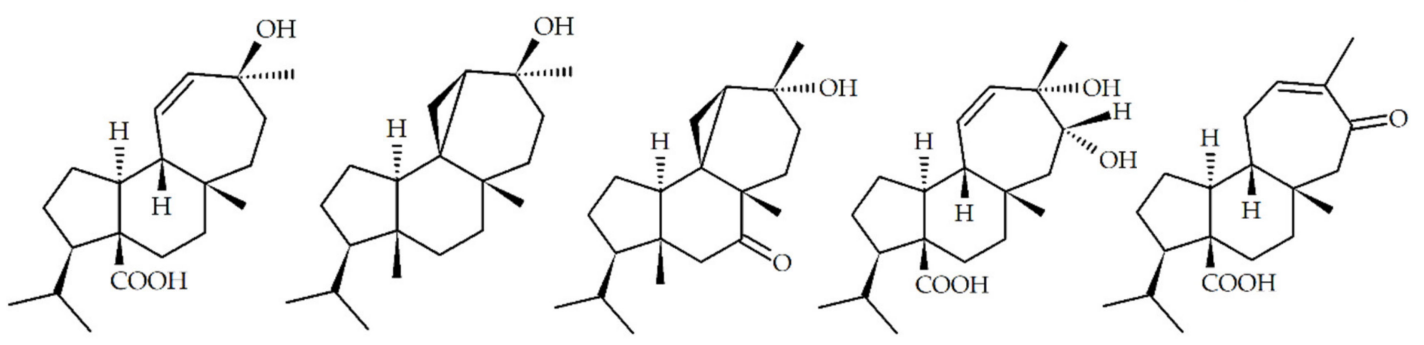

14

15

17

18

19

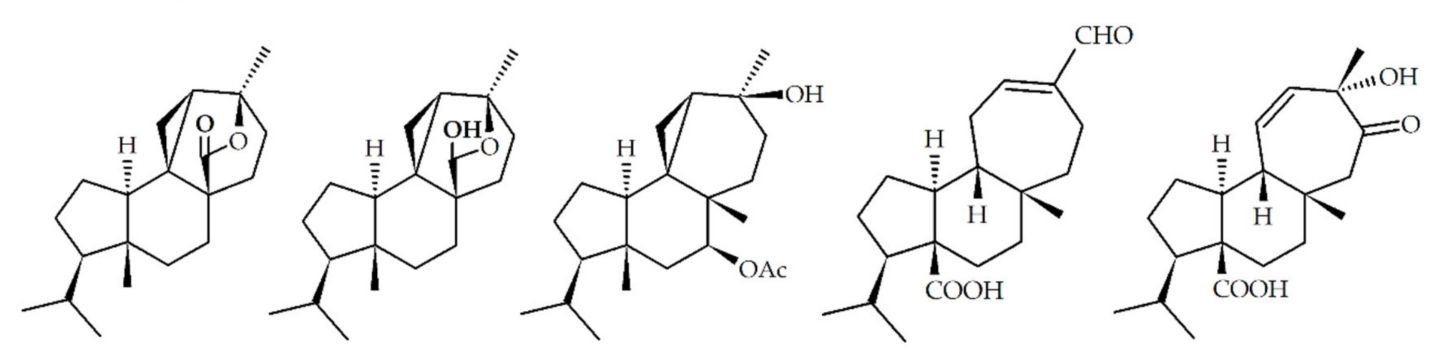

22

23

26

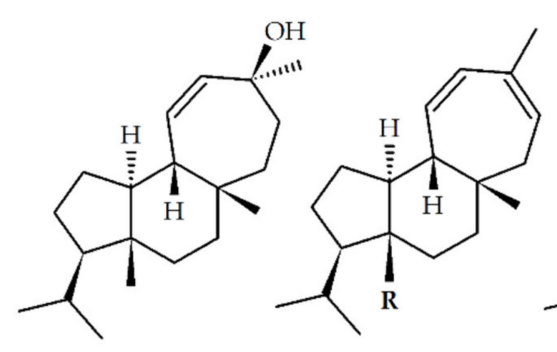

28

$29 \mathrm{R}=\mathrm{CH}_{2} \mathrm{OH}$

$40 \mathrm{R}=\mathrm{CH}_{3}$

24

25

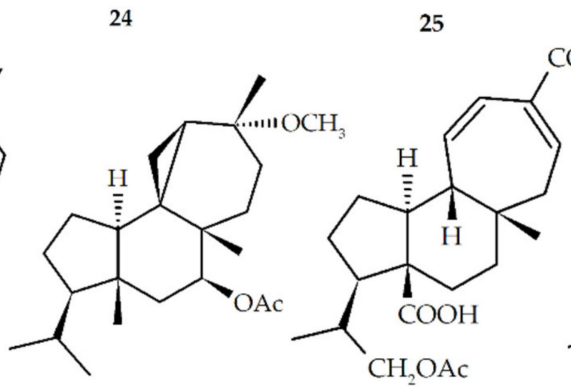

30

31

Figure 3. Cont. 


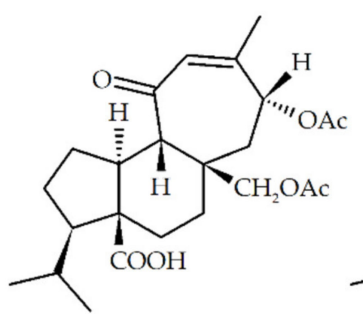

33<smiles>C=C1C=C[C@H]2[C@H](CC[C@@H]2C(C)C)[C@@]2(C(=O)O)CC[C@H](C(C)C)[C@@H]1C[C@@H]2O</smiles>

37

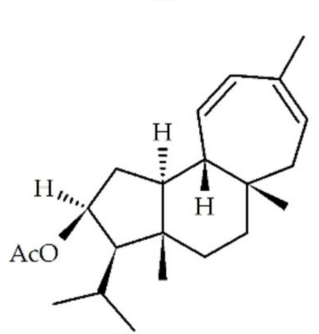

42

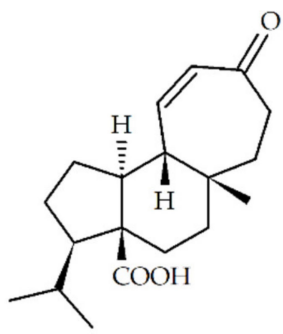

47

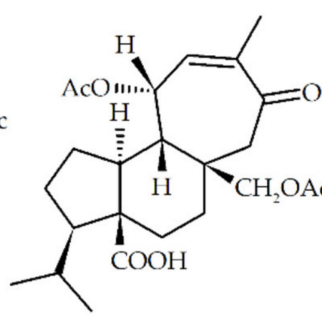

34

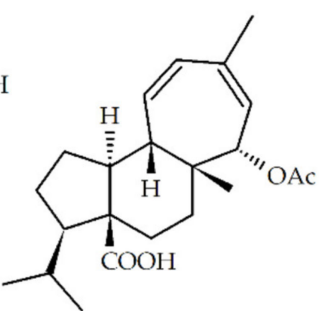

38

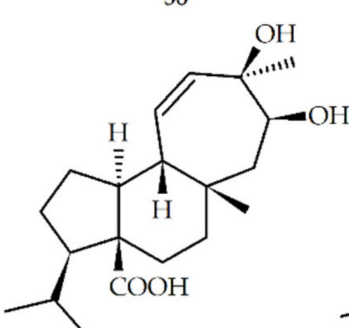

43

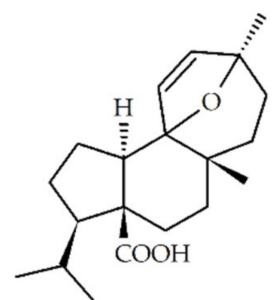

48

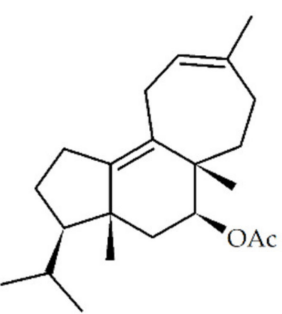

35

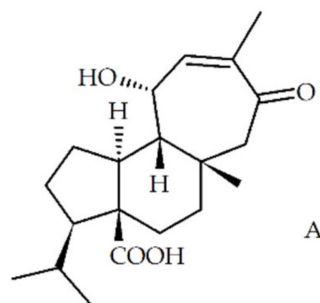

39

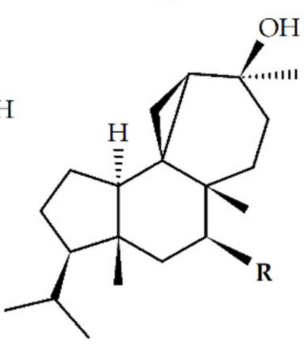

$$
44 \mathrm{R}==\mathrm{O}
$$

$45 \mathrm{R}=\mathrm{OH}$

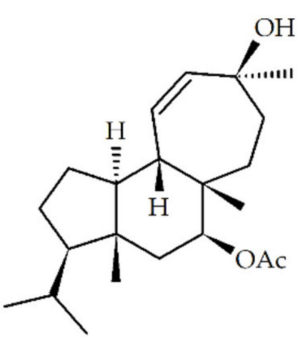

36

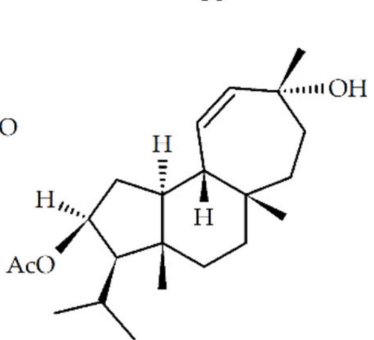

41

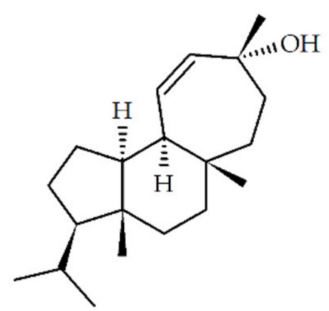

46

Figure 3. Natural mulinane and azorellane diterpenoids.

\section{Synthetic, Semisynthetic, and Biotransformed Mulinane and Azorellane Diterpenoids}

Recently, Liu et al. achieved the enantioselective total synthesis of natural mulinanes and analogous from cyclopentenone (Table 2, and Figure 4) [53]. In addition, the presence of different functional groups, which include hydroxyl, carboxyl, acetoxy, and double bond, in the mulinane skeleton has allowed the preparation of a significant number of semisynthetic derivatives using dehydration, alkylation, hydrolysis, and oxidation reactions (Table 3, and Figure 5). To date, only one semisynthetic azorellane derivative, $7 \beta$-deacetylazorellanol (16), has been reported; this can be explained by the fact that the cyclopropane ring in the azorellane skeleton can be easily open under weak acidic conditions, to produce semisynthetic derivatives having a mulinane skeleton [54]. However, the limited number of functionalized positions, and the type of functional groups, found in the chemical structures of natural azorellane and mulinane diterpenoids limit the number and type of semisynthetic derivatives that can be prepared through chemical modification [55]; because of this, in recent years, biotransformation using filamentous fungi such as Mucor plumbeus and M. circinelloides has been explored as a new strategy to obtain novel mulinane and azorellane derivatives $[51,55,56]$ (Table 4, Figure 6). 
Table 2. Synthetic derivatives of mulinanes [53].

\begin{tabular}{|c|c|}
\hline No & Synthetic Mulinanes \\
\hline $1 *$ & Mulinic acid (mulin-11,14-peroxi-12-en-20-oic acid) \\
\hline $2 *$ & Isomulinic acid (mulin-11,12,13,14-diepoxy-20-oic acid) \\
\hline 6 * & mulin11,13-dien-20-oic acid \\
\hline 14 * & 13 $\beta$-epimulinolic acid (mulin-13 $\beta$-hydroxy-11-en-20-oic acid) \\
\hline 21 * & 20-hydroxymulin-11,13-dienyl acetate (mulin-11,13-dien-20-yl acetate) \\
\hline 50 & 16-hydroxy-mulin-11,13-dien-20-oic acid (mulin-16-hydroxy-11,13-dien-20-oic acid) \\
\hline 51 & Mulin-11,13-dien-20-ol \\
\hline 52 & 13 $\beta$-epi-mulinol (mulin-11-en-13 $\beta, 20$-diol) \\
\hline 53 & $13 \beta$-epi-mulinolic acid ethyl ester (mulin-13 $\beta$-hydroxy-11-en-20-oic acid ethyl ester) \\
\hline
\end{tabular}

Table 3. Semisynthetic derivatives of mulinanes.

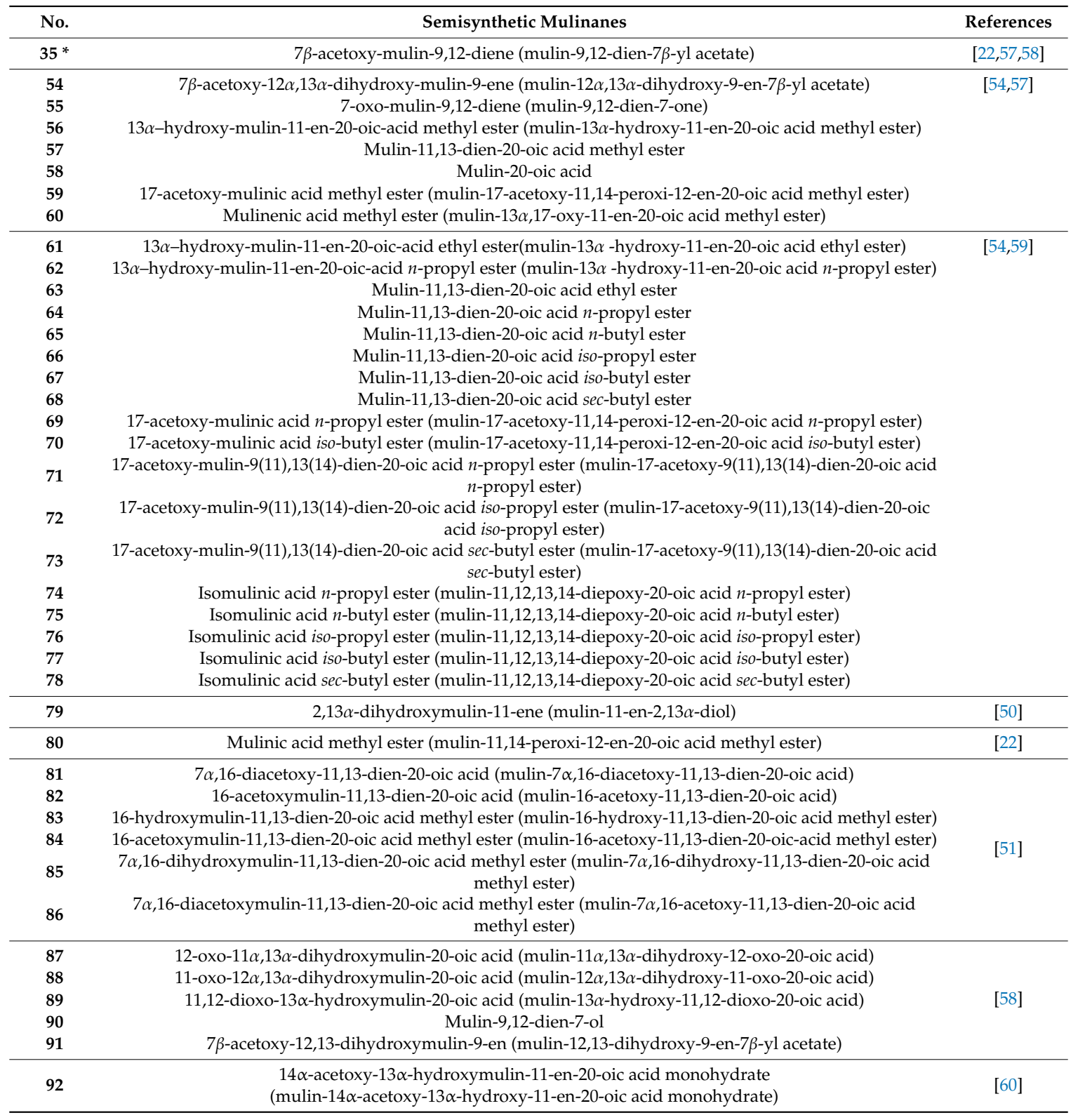




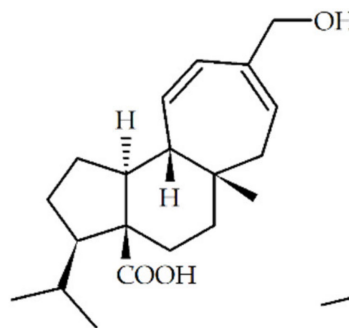

50

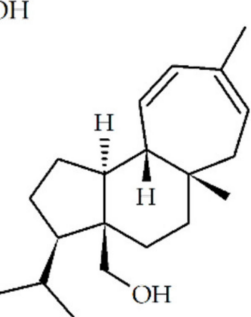

51

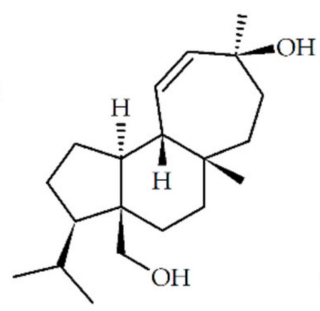

52

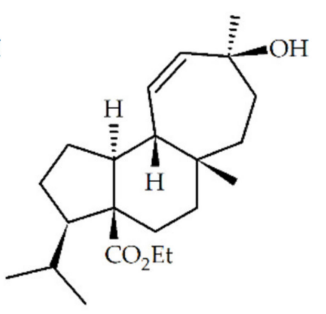

53

Figure 4. Synthetic mulinanes diterpenoids.<smiles>CC(C)C1CCC2=C3C[C@H](O)[C@@](C)(O)CCC3(C)C(O)CC21C</smiles>

54

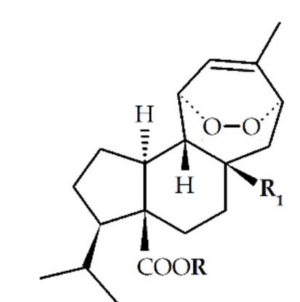

$59 \mathrm{R}=\mathrm{CH}_{3}, \mathrm{R}_{1}=\mathrm{CH}_{2} \mathrm{OAC}$ $69 \mathrm{R}=\mathrm{CH}_{2} \mathrm{CH}_{2} \mathrm{CH}_{3}, \mathrm{R}_{1}=\mathrm{CH}_{2} \mathrm{OAc}$ $70 \mathbf{R}=\mathrm{CH}_{2} \mathrm{CH}\left(\mathrm{CH}_{3}\right)_{2}, \mathrm{R}_{1}=\mathrm{CH}_{2} \mathrm{OAC}$ $80 \mathrm{R}=\mathrm{CH}_{3}, \mathrm{R}_{1}=\mathrm{CH}_{3}$<smiles>CC(C)C1[C@H](C)CC[C@@]2(C)CC[C@@](C)(O)C=C[C@@H]2C[C@H]1O</smiles>

79 $\begin{array}{ll}81 \mathbf{R}=\mathrm{H}, & \mathbf{R}_{1}=\mathrm{OAC}, \quad \mathbf{R}_{2}=\mathrm{OAC} \\ 82 \mathbf{R}=\mathrm{H}, & \mathbf{R}_{1}=\mathrm{H}, \quad \mathbf{R}_{2}=\mathrm{OAC}\end{array}$ $83 \mathbf{R}=\mathrm{CH}_{3}, \quad \mathbf{R}_{1}=\mathrm{H}, \quad \mathbf{R}_{2}=\mathrm{H}$ $84 \mathbf{R}=\mathrm{CH}_{3}, \quad \mathbf{R}_{1}=\mathrm{H}, \quad \mathbf{R}_{2}=\mathrm{OAc}$ $85 \mathrm{R}=\mathrm{CH}_{3}, \quad \mathrm{R}_{1}=\mathrm{OAc}, \quad \mathbf{R}_{2}=\mathrm{OAC}$ $86 \mathrm{R}=\mathrm{CH}_{3}, \quad \mathrm{R}_{1}=\mathrm{OH}, \quad \mathbf{R}_{2}=\mathrm{OH}$

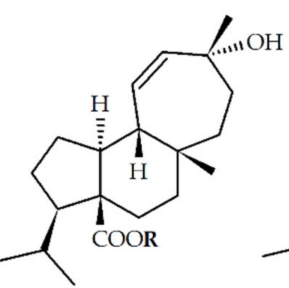

$56 \mathrm{R}=\mathrm{CH}_{3}$ $61 \mathrm{R}=\mathrm{CH}_{2} \mathrm{CH}_{3}$ $62 \mathrm{R}=\mathrm{CH}_{2} \mathrm{CH}_{2} \mathrm{CH}_{3}$

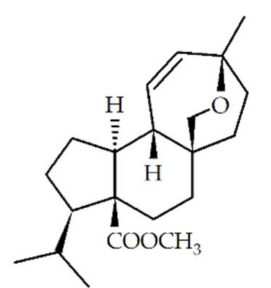

60

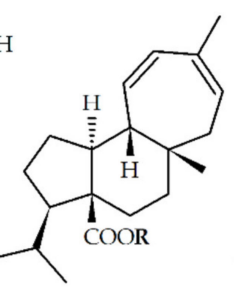

$57 \mathrm{R}=\mathrm{CH}_{3}$ $63 \mathrm{R}=\mathrm{CH}_{2} \mathrm{CH}$ $64 \mathrm{R}=\mathrm{CH}_{2}^{2} \mathrm{CH}_{2} \mathrm{CH}_{3}$ $65 \mathrm{R}=\mathrm{CH}_{2}\left(\mathrm{CH}_{2}\right)_{2} \mathrm{CH}_{3}$ $66 \mathrm{R}=\mathrm{CH}_{2}\left(\mathrm{CH}_{3}\right)_{2}$ $67 \mathrm{R}=\mathrm{CH}_{2} \mathrm{CH}_{2}\left(\mathrm{CH}_{3}\right)_{2}$ $68 \mathrm{R}=\mathrm{CHCH}_{2} \mathrm{CH}_{3}$ $\mathrm{CH}_{3}$<smiles>[R]OC(=O)[C@]1(C)CC[C@]2(COC(C)=O)CC=C(C)CC=C2[C@H]1C(C)C</smiles>

$71 \mathrm{R}=\mathrm{CH}_{2} \mathrm{CH}_{2} \mathrm{CH}_{3}$ $72 \mathrm{R}=\mathrm{CH}\left(\mathrm{CH}_{3}\right)_{2}$ $73 \mathrm{R}=\mathrm{CH}\left(\mathrm{CH}_{3}\right)_{3}$

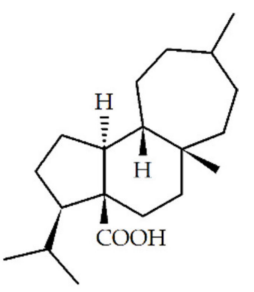

58

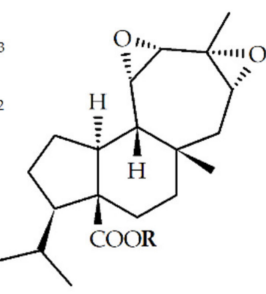

$74 \mathrm{R}=\mathrm{CH}_{2} \mathrm{CH}_{2} \mathrm{CH}_{3}$ $75 \mathrm{R}=\mathrm{CH}_{2}\left(\mathrm{CH}_{2}\right)_{2} \mathrm{CH}_{3}$ $76 \mathrm{R}=\mathrm{CH}\left(\mathrm{CH}_{3}\right)_{2}$ $77 \mathrm{R}=\mathrm{CH}_{2} \mathrm{CH}\left(\mathrm{CH}_{3}\right)_{2}$ $78 \mathrm{R}=\mathrm{CHCH}_{2} \mathrm{CH}_{3}$ $\mathrm{CH}_{3}$

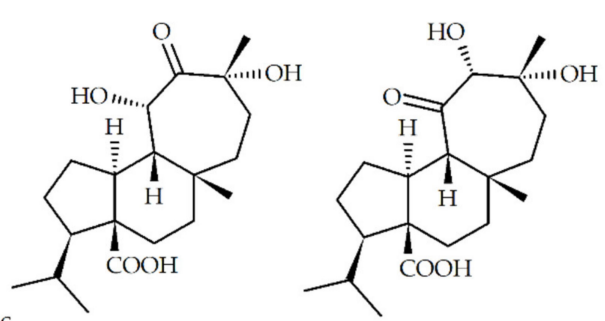

87 88

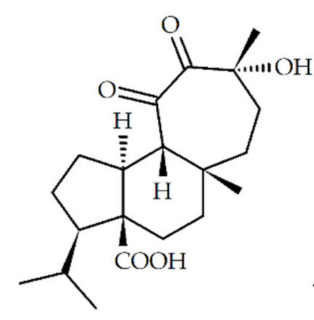

89

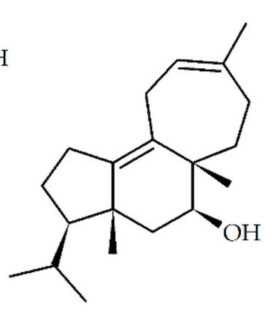

90

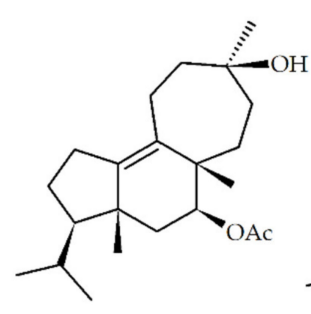

91

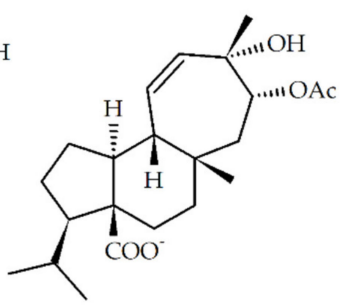

92

Figure 5. Semisynthetic mulinane diterpenoids. 
Table 4. Mulinane derivatives obtained through biotransformation.

\begin{tabular}{|c|c|c|}
\hline No. & Biotransformed Mulinanes & References \\
\hline $50 *$ & $\begin{array}{l}\text { 16-hydroxy-mulin-11,13-dien-20-oic acid } \\
\text { (mulin-16-hydroxy-11,13-dien-20-oic acid) }\end{array}$ & \multirow[t]{2}{*}[51,56]{} \\
\hline 93 & $\begin{array}{l}\text { 7 } \alpha, 16 \text {-dihydroxymulin-11,13-dien-20-oic acid } \\
\text { (mulin-7 } \alpha, 16 \text {-dihydroxy-11,13-dien-20-oic acid) }\end{array}$ & \\
\hline 94 & Mulin-11,13-dien-16,20-oic acid & \multirow{2}{*}{ [55] } \\
\hline \multirow[t]{4}{*}{95} & $\begin{array}{l}7 \alpha, 13 \beta \text {-dihydroxymulin-11-en-dien-20-oic acid } \\
\text { (mulin-7 } 2,13 \beta \text {-dihydroxy-11-en-dien-20-oic acid) }\end{array}$ & \\
\hline & * Previously reported as natural product. & \\
\hline & $\mathrm{CH}_{2} \mathrm{OH}$ & $\mathrm{OH}$ \\
\hline & 9 & \\
\hline
\end{tabular}

Figure 6. Biotransformed mulinane diterpenoids.

\section{Pharmacological Activities of Mulinane and Azorellane Diterpenoids}

Despite the development of drugs for treating diseases such as HIV/AIDS, malaria, tuberculosis, hypertension, diabetes, and cancer, these diseases continue to affect diverse populations worldwide with significant associated mortalities and the need to develop new and more effective pharmaceuticals is always present [61]. Currently, the importance of natural products and/or its derivatives in drug discovery and development is well recognized $[8,62]$. Since the structurally-unique mulinanes and azorellanes have displayed a wide variety of biological activities in both in vitro and in vivo pharmacological models, the preparation of mulinane and azorellane derivatives could yield new products with a stronger biological activity, a better solubility, or useful in determining structure-activity relationships or mode-of-action [63]. A summary of the pharmacological activities reported for mulinanes and azorellanes is listed in Table 5.

\subsection{Antimicrobial Activity}

Since the initial discovery of antibiotics in the 1930s, and perhaps until the 1980s, the prevailing view was that virtually all bacterial infections could be treated effectively with antibiotics. The spread of antimicrobial resistance has generated a growing concern in the medical community and in the public. The rate of persons dying due to the lack of effective antimicrobials is growing; it has been estimated that the number of deaths occurring worldwide due to drug resistance could rise to as many as 10 million individuals in 2050 [62]. Hence, the development of new antibiotics is needed. A number of mulinane and azorellane diterpenoids have displayed significant antimycobacterial and antibacterial activities, e.g., azorellan-13 $\beta$-ol (15) from Azorella madreporica showed activity against Mycobacterium tuberculosis (H37Rv) with a minimal inhibitory concentration (MIC) $=20 \mu \mathrm{g} / \mathrm{mL}$ in the BD BACTEC MGIT 960 system [46]. Natural mulinanes and azorellanes isolated from A. compacta, A. madreporica, M. crassifolium, and Laretia acaulis, together with a number of semisynthetic derivatives, were evaluated against susceptible M. tuberculosis (H37Rv) and MDR (resistant to Streptomycin, Isoniazid, Rifampin, Ethambutol, and Pyrazinamide) clinical isolate using the Microplate Blue Alamar Assay (MABA). The natural mulin-11-en-13 $\alpha, 20$-diol (8), azorellanol (9), 13 $\beta$-hydroxyazorellane (15), azorellanone (17), 17-acetoxy-13- $\alpha$-hydroxyazorellane (27), semisynthetic 13 $\alpha$-hydroxy-mulin-11-en-20-oic-acid 
methyl ester (56), mulin-11,13-dien-20-oic acid methyl ester (57), and mulinenic acid methyl ester (60) were the most active against both strains (MIC $=12.5-25 \mu \mathrm{g} / \mathrm{mL}$ ) [54,57], taking into account that a MIC of $\leq 64 \mu \mathrm{g} / \mathrm{mL}$ is considered promising for a pure product [64]. Preparation of several C-20 alkylated mulinane derivatives confirmed reports that methylation of the C-20 carboxyl group of the mulinane skeleton improves activity [59]; the most active derivatives, with MIC values between $6.25 \mathrm{and} 25 \mu \mathrm{g} / \mathrm{mL}$ against the drug-sensitive and drug-resistant strains of $M$. tuberculosis, included $13 \alpha$-hydroxy-mulin-11-en-20-oic acid $n$-propyl-ester (62), the isomulinic acid $n$-propyl ester (74), and the isomulinic acid $n$-butyl ester (75). The results also demonstrated that linear esters of mulinanes had better antituberculosis activity than their branched counterparts [59]. Similarly, the semisynthetic derivative $7 \beta$-acetoxy-mulin-9,12-diene (35) showed antimycobacterial activity (MIC $=43.8 \mu \mathrm{g} / \mathrm{mL}$ ) when tested against M. smegmatis, as well as antimicrobial activity against Staphylococcus aureus (ATCC 25923) and MDR (resistant to Ampicillin-sulbactam, Cefoxitin, Cephalotin, Cephazolin, Ciprofloxacin, Clindamycin, Erythromycin, and Trimethoprim-sulfamethoxazole) strains [22]. Other metabolites, such as mulin-12,14-dien-11-on-20-oic acid (12) and mulin-12-ene-11,14-dion-20-oic acid (13), both isolated from $A$. compacta, exhibited activity against Methicillin-resistant and -susceptible strains of S. aureus, as well as Vancomycin-resistant and -susceptible strains of Enterococcus faecium and Escherichia coli [40].

\subsection{Antiprotozoal Activity}

Parasitic diseases are a serious health problem that has had a deep impact on the global human population [65]. Among parasites, protozoal parasites such as Trypanosoma cruzi, Leishmania spp., Plasmodium falciparum, Giardia intestinalis, Trichomonas vaginalis, and Toxoplasma gondii, represent the major disease-causing organisms $[65,66]$. The infections caused by these parasites are responsible for 500 million deaths worldwide, especially in undeveloped countries, where a tropical or temperate climate and poor sanitary and hygiene conditions are common [67]. Globally, the burden of protozoal diseases is increasing and has been exacerbated by the limited number of pharmaceuticals available, the lack of effective medication due to drug resistance, the severity of side effects, the high costs, or their limited practicality for field use. These limitations have prompted many researchers to search for novel drugs against protozoal parasites $[65,67]$. Diverse studies provide support that mulinanes and azorellane represent a promising group of natural antiprotozoal agents [21,29,35,41]. Azorellanol (9) and mulin-11,13-dien-20-oic acid (6), both isolated from A. compacta, showed strong in vitro trypanocidal activity $\left(\mathrm{IC}_{50}\right.$ values of $\left.20-87 \mu \mathrm{M}\right)$ when tested against epimastigotes, trypomastigotes, and amastigotes of different strains (Tulahuen, SPA-14, and CL Brener) of T. cruzi. Both metabolites also showed activity against intracellular amastigotes of the CL Brener clone with an $\mathrm{IC}_{50}$ of $32.3 \mu \mathrm{M}$ and $29 \mu \mathrm{M}$, respectively [21]. Additionally, azorellanol (9) also had an effect on trophozoites of T. vaginalis Ant-1 strain $\left(\mathrm{LD}_{50}=40.5 \mathrm{mM}\right)$ and T. gondii $\left(\mathrm{ID}_{50}=54 \mathrm{mM}\right)$, but $7 \beta$-deacetylazorellanol $(16)$ showed a stronger activity $\left(\mathrm{ID}_{50}=42 \mathrm{mM}\right)$ against $T$. gondii [35,41]. Finally, 17-acetoxymulin-11,13-dien-20-oic acid (20) and 13 $\alpha, 14 \alpha$-dihydroxymulin-11-en-20-oic acid (18), both from A. compacta, caused $60 \%$ and $42 \%$ growth inhibition of Plasmodium berghei NK 65 in infected mice, respectively, when tested at a dose of $10 \mathrm{mg} / \mathrm{kg} /$ day [29]. 
Table 5. Pharmacological activities of mulinanes and azorellanes. MIC: Minimal Inhibitory Concentration; ZI: Zone of inhibition; LD50: Median Lethal Dose; \%: Percentage of Inhibition; $\mathrm{IC}_{50}$ : Median Inhibitory Concentration; \%MC: Percentage of Motility Cells; \%LC: Percentage of Living Cells.

\begin{tabular}{|c|c|c|c|c|c|c|c|}
\hline Activity & Study Model & Compound (Number) & Skeleton Type & Compound Origin & Biological Result & Positive Control & References \\
\hline \multirow{29}{*}{ Antimicrobial } & \multirow{29}{*}{$\begin{array}{l}\text { Mycobacterium } \\
\text { tuberculosis H37Rv } \\
\text { (ATCC 27294) }\end{array}$} & 13 $\alpha$-hydroxyazorellane (11) & A & $\mathrm{N}$ & $\mathrm{MIC}=20 \mu \mathrm{g} / \mathrm{mL}$ & $\begin{array}{l}\text { Rifampin } \\
\text { MIC }=0.125 \mu \mathrm{g} / \mathrm{mL}\end{array}$ & [46] \\
\hline & & 13ß-hydroxyazorellane (15) & A & $\mathrm{N}$ & MIC $=12.5 \mu \mathrm{g} / \mathrm{mL}$ & \multirow{12}{*}{$\begin{array}{l}\text { Rifampin } \\
\text { MIC }=0.062 \mu \mathrm{g} / \mathrm{mL} \\
\text { Ofloxacin } \\
\text { MIC }=0.125 \mu \mathrm{g} / \mathrm{mL}\end{array}$} & \multirow{12}{*}{ [57] } \\
\hline & & Azorellanol (9) & A & $\mathrm{N}$ & MIC $=12.5 \mu \mathrm{g} / \mathrm{mL}$ & & \\
\hline & & 17-acetoxy-13 $\alpha$-hydroxyazorellane (27) & A & $\mathrm{N}$ & MIC $=12.5 \mu \mathrm{g} / \mathrm{mL}$ & & \\
\hline & & $7 \beta$-deacetylazorellanol (16) & A & $\mathrm{N}$ & $\mathrm{MIC}=25 \mu \mathrm{g} / \mathrm{mL}$ & & \\
\hline & & Azorellanone (17) & A & $\mathrm{N}$ & $\mathrm{MIC}=12.5 \mu \mathrm{g} / \mathrm{mL}$ & & \\
\hline & & Mulin-11,13-dien-20-oic acid (6) & $\mathrm{M}$ & $\mathrm{M}$ & MIC $=50 \mu \mathrm{g} / \mathrm{mL}$ & & \\
\hline & & Mulinic acid (1) & $\mathrm{M}$ & $\mathrm{N}$ & $\mathrm{MIC}=50 \mu \mathrm{g} / \mathrm{mL}$ & & \\
\hline & & Mulinol (8) & $\mathrm{M}$ & $\mathrm{N}$ & MIC $=25 \mu \mathrm{g} / \mathrm{mL}$ & & \\
\hline & & $7 \beta$-acetoxy-12 $\alpha, 13 \alpha$-dihydroxy-mulin-9-ene (54) & M & SS & $\mathrm{MIC}=25 \mu \mathrm{g} / \mathrm{mL}$ & & \\
\hline & & 13 $\alpha$-hydroxy-mulin-11-en-20-oic-acid methyl ester (56) & M & SS & MIC $=12.5 \mu \mathrm{g} / \mathrm{mL}$ & & \\
\hline & & Mulin-11,13-dien-20-oic acid methyl ester (57) & M & SS & $\mathrm{MIC}=25 \mu \mathrm{g} / \mathrm{mL}$ & & \\
\hline & & Mulinenic acid methyl ester (60) & $\mathrm{M}$ & SS & $\mathrm{MIC}=12.5 \mu \mathrm{g} / \mathrm{mL}$ & & \\
\hline & & $13 \alpha$-hydroxy-mulin-11-en-20-oic-acid ethyl ester (61) & $\mathrm{M}$ & SS & MIC $=25 \mu \mathrm{g} / \mathrm{mL}$ & \multirow{16}{*}{$\begin{array}{l}\text { Rifampin MIC = } \\
0.062 \mu \mathrm{g} / \mathrm{mL} \\
\text { Ofloxacin MIC = } \\
0.125 \mu \mathrm{g} / \mathrm{mL}\end{array}$} & \multirow{16}{*}{ [59] } \\
\hline & & $13 \alpha$-hydroxy-mulin-11-en-20-oic-acid n-propyl ester (62) & M & SS & MIC $=25 \mu \mathrm{g} / \mathrm{mL}$ & & \\
\hline & & Mulin-11,13-dien-20-oic acid ethyl ester (63) & $\mathrm{M}$ & SS & $\mathrm{MIC}=25 \mu \mathrm{g} / \mathrm{mL}$ & & \\
\hline & & Mulin-11,13-dien-20-oic acid $n$-propyl ester (64) & M & SS & $\mathrm{MIC}=25 \mu \mathrm{g} / \mathrm{mL}$ & & \\
\hline & & Mulin-11,13-dien-20-oic acid $n$-butyl ester (65) & M & SS & $\mathrm{MIC}=25 \mu \mathrm{g} / \mathrm{mL}$ & & \\
\hline & & Mulin-11,13-dien-20-oic acid iso-propyl ester (66) & M & SS & $\mathrm{MIC}=50 \mu \mathrm{g} / \mathrm{mL}$ & & \\
\hline & & Mulin-11,13-dien-20-oic acid iso-butyl ester (67) & $\mathrm{M}$ & SS & $\mathrm{MIC}=50 \mu \mathrm{g} / \mathrm{mL}$ & & \\
\hline & & Mulin-11,13-dien-20-oic acid sec-butyl ester (68) & $\mathrm{M}$ & SS & $\mathrm{MIC}=50 \mu \mathrm{g} / \mathrm{mL}$ & & \\
\hline & & 17-acetoxy-mulinic acid $n$-propyl ester (69) & $\mathrm{M}$ & SS & $\mathrm{MIC}=50 \mu \mathrm{g} / \mathrm{mL}$ & & \\
\hline & & 17-acetoxy-mulinic acid iso-butyl ester (70) & M & SS & $\mathrm{MIC}=50 \mu \mathrm{g} / \mathrm{mL}$ & & \\
\hline & & 17-acetoxy-mulin-9(11),13(14)-dien-20-oic acid iso-propyl ester (72) & M & SS & $\mathrm{MIC}=50 \mu \mathrm{g} / \mathrm{mL}$ & & \\
\hline & & 17-acetoxy-mulin-9(11),13(14)-dien-20-oic acid sec-butyl ester (73) & $\mathrm{M}$ & SS & $\mathrm{MIC}=50 \mu \mathrm{g} / \mathrm{mL}$ & & \\
\hline & & Isomulinic acid $n$-propyl ester (74) & $\mathrm{M}$ & SS & $\mathrm{MIC}=25 \mu \mathrm{g} / \mathrm{mL}$ & & \\
\hline & & Isomulinic acid $n$-butyl ester (75) & $\mathrm{M}$ & SS & $\mathrm{MIC}=25 \mu \mathrm{g} / \mathrm{mL}$ & & \\
\hline & & Isomulinic acid iso-propyl ester (76) & $\mathrm{M}$ & SS & MIC $=50 \mu \mathrm{g} / \mathrm{mL}$ & & \\
\hline & & Isomulinic acid iso-butyl ester (77) & $\mathrm{M}$ & SS & $\mathrm{MIC}=50 \mu \mathrm{g} / \mathrm{mL}$ & & \\
\hline
\end{tabular}


Table 5. Cont

\begin{tabular}{|c|c|c|c|c|c|c|c|}
\hline Activity & Study Model & Compound (Number) & Skeleton Type & Compound Origin & Biological Result & Positive Control & References \\
\hline \multirow{31}{*}{ Antimicrobial } & \multirow{31}{*}{$\begin{array}{l}\text { M. tuberculosis } \\
\text { clinical isolate } \\
\text { (MDR) }\end{array}$} & 13ß-hydroxyazorellane (15) & $\mathrm{M}$ & $\mathrm{N}$ & $\mathrm{MIC}=25 \mu \mathrm{g} / \mathrm{mL}$ & \multirow{19}{*}{$\begin{array}{l}\text { Ofloxacin MIC = } \\
0.250 \mu \mathrm{g} / \mathrm{mL}\end{array}$} & \multirow{19}{*}{ [57] } \\
\hline & & Azorellanol (9) & $\mathrm{A}$ & $\mathrm{N}$ & MIC $=12.5 \mu \mathrm{g} / \mathrm{mL}$ & & \\
\hline & & 17-acetoxy-13 $\alpha$-hydroxyazorellane (27) & A & $\mathrm{N}$ & $\mathrm{MIC}=12.5 \mu \mathrm{g} / \mathrm{mL}$ & & \\
\hline & & $7 \beta$-deacetylazorellanol (16) & $\mathrm{A}$ & $\mathrm{N}$ & $\mathrm{MIC}=25 \mu \mathrm{g} / \mathrm{mL}$ & & \\
\hline & & Azorellanone (17) & $\mathrm{A}$ & $\mathrm{N}$ & $\mathrm{MIC}=25 \mu \mathrm{g} / \mathrm{mL}$ & & \\
\hline & & 13ß-epiazorellanol (24) & A & $\mathrm{N}$ & $\mathrm{MIC}=50 \mu \mathrm{g} / \mathrm{mL}$ & & \\
\hline & & mulin-13 $\alpha$-hydroxy-11-en-20-oic acid (5) & $\mathrm{M}$ & $\mathrm{N}$ & $\mathrm{MIC}=50 \mu \mathrm{g} / \mathrm{mL}$ & & \\
\hline & & Mulin-11,13-dien-20-oic acid (6) & $\mathrm{M}$ & $\mathrm{N}$ & $\mathrm{MIC}=25 \mu \mathrm{g} / \mathrm{mL}$ & & \\
\hline & & 13 $\alpha, 14 \alpha$-dihydroxy-mulin-11-en-20-oic acid (18) & $\mathrm{M}$ & $\mathrm{N}$ & $\mathrm{MIC}=50 \mu \mathrm{g} / \mathrm{mL}$ & & \\
\hline & & Mulinic acid (1) & M & $\mathrm{N}$ & $\mathrm{MIC}=25 \mu \mathrm{g} / \mathrm{mL}$ & & \\
\hline & & 17-acetoxymulinic acid (3) & $\mathrm{M}$ & $\mathrm{N}$ & $\mathrm{MIC}=50 \mu \mathrm{g} / \mathrm{mL}$ & & \\
\hline & & Mulinol (8) & M & $\mathrm{N}$ & MIC $=12.5 \mu \mathrm{g} / \mathrm{mL}$ & & \\
\hline & & $7 \beta$-acetoxy-12 $\alpha, 13 \alpha$-dihydroxy-mulin-9-ene (54) & M & SS & $\mathrm{MIC}=25 \mu \mathrm{g} / \mathrm{mL}$ & & \\
\hline & & 7-oxo-mulin-9,12-diene (55) & M & SS & $\mathrm{MIC}=50 \mu \mathrm{g} / \mathrm{mL}$ & & \\
\hline & & $13 \alpha$-hydroxy-mulin-11-en-20-oic-acid methyl ester (56) & $\mathrm{M}$ & SS & MIC $=12.5 \mu \mathrm{g} / \mathrm{mL}$ & & \\
\hline & & Mulin-11,13-dien-20-oic acid methyl ester (57) & M & SS & MIC $=12.5 \mu \mathrm{g} / \mathrm{mL}$ & & \\
\hline & & Mulin-20-oic acid (58) & $\mathrm{M}$ & SS & $\mathrm{MIC}=50 \mu \mathrm{g} / \mathrm{mL}$ & & \\
\hline & & 17-acetoxy-mulinic acid methyl ester (59) & $\mathrm{M}$ & SS & $\mathrm{MIC}=50 \mu \mathrm{g} / \mathrm{mL}$ & & \\
\hline & & Mulinenic acid methyl ester (60) & $\mathrm{M}$ & SS & MIC $=12.5 \mu \mathrm{g} / \mathrm{mL}$ & & \\
\hline & & 13 $\alpha$-hydroxy-mulin-11-en-20-oic-acid ethyl ester (61) & M & SS & MIC $=12.5 \mu \mathrm{g} / \mathrm{mL}$ & \multirow{12}{*}{$\begin{array}{l}\text { Ofloxacin MIC = } \\
0.250 \mu \mathrm{g} / \mathrm{mL}\end{array}$} & \multirow{12}{*}{ [59] } \\
\hline & & $13 \alpha$-hydroxy-mulin-11-en-20-oic-acid $n$-propyl ester (62) & $\mathrm{M}$ & SS & $\mathrm{MIC}=6.25 \mu \mathrm{g} / \mathrm{mL}$ & & \\
\hline & & Mulin-11,13-dien-20-oic acid ethyl ester (63) & M & SS & MIC $=12.5 \mu \mathrm{g} / \mathrm{mL}$ & & \\
\hline & & Mulin-11,13-dien-20-oic acid $n$-propyl ester (64) & M & SS & MIC $=12.5 \mu \mathrm{g} / \mathrm{mL}$ & & \\
\hline & & Mulin-11,13-dien-20-oic acid $n$-butyl ester (65) & M & SS & MIC $=12.5 \mu \mathrm{g} / \mathrm{mL}$ & & \\
\hline & & Mulin-11,13-dien-20-oic acid iso-propyl ester (66) & $\mathrm{M}$ & SS & $\mathrm{MIC}=25 \mu \mathrm{g} / \mathrm{mL}$ & & \\
\hline & & Mulin-11,13-dien-20-oic acid iso-butyl ester (67) & $\mathrm{M}$ & SS & $\mathrm{MIC}=25 \mu \mathrm{g} / \mathrm{mL}$ & & \\
\hline & & Mulin-11,13-dien-20-oic acid sec-butyl ester (68) & $\mathrm{M}$ & SS & $\mathrm{MIC}=25 \mu \mathrm{g} / \mathrm{mL}$ & & \\
\hline & & 17-acetoxy-mulinic acid $n$-propyl ester (69) & $\mathrm{M}$ & SS & $\mathrm{MIC}=12.5 \mu \mathrm{g} / \mathrm{mL}$ & & \\
\hline & & 17-acetoxy-mulinic acid iso-butyl ester (70) & $\mathrm{M}$ & SS & $\mathrm{MIC}=25 \mu \mathrm{g} / \mathrm{mL}$ & & \\
\hline & & 17-acetoxy-mulin-9(11),13(14)-dien-20-oic acid $n$-propyl ester (71) & M & SS & $\mathrm{MIC}=50 \mu \mathrm{g} / \mathrm{mL}$ & & \\
\hline & & 17-acetoxy-mulin-9(11),13(14)-dien-20-oic acid iso-propyl ester (72) & M & SS & $\mathrm{MIC}=25 \mu \mathrm{g} / \mathrm{mL}$ & & \\
\hline
\end{tabular}


Table 5. Cont.

\begin{tabular}{|c|c|c|c|c|c|c|c|}
\hline Activity & Study Model & Compound (Number) & Skeleton Type & Compound Origin & Biological Result & Positive Control & References \\
\hline \multirow{17}{*}{ Antimicrobial } & & 17-acetoxy-mulin-9(11),13(14)-dien-20-oic acid sec-butyl ester (73) & $\mathrm{M}$ & SS & $\mathrm{MIC}=25 \mu \mathrm{g} / \mathrm{mL}$ & & \\
\hline & & Isomulinic acid $n$-propyl ester (74) & $\mathrm{M}$ & SS & MIC $=6.25 \mu \mathrm{g} / \mathrm{mL}$ & & \\
\hline & & Isomulinic acid $n$-butyl ester (75) & $\mathrm{M}$ & SS & MIC $=6.25 \mu \mathrm{g} / \mathrm{mL}$ & & \\
\hline & & Isomulinic acid iso-propyl ester (76) & $\mathrm{M}$ & SS & $\mathrm{MIC}=12.5 \mu \mathrm{g} / \mathrm{mL}$ & & \\
\hline & & Isomulinic acid iso-butyl ester (77) & $\mathrm{M}$ & SS & $\mathrm{MIC}=12.5 \mu \mathrm{g} / \mathrm{mL}$ & & \\
\hline & & Isomulinic acid sec-butyl ester (78) & $\mathrm{M}$ & SS & $\mathrm{MIC}=50 \mu \mathrm{g} / \mathrm{mL}$ & & \\
\hline & $\begin{array}{l}\text { M. smegmatis } \\
\text { (ATCC 14468) }\end{array}$ & $7 \beta$-acetoxy-mulin-9,12-diene (35) & M & SS & $\mathrm{MIC}=43.8 \mu \mathrm{g} / \mathrm{mL}$ & No data & [22] \\
\hline & $\begin{array}{l}\text { Staphylococcus } \\
\text { aureus MSSA } \\
\text { (ATCC 25923) }\end{array}$ & $7 \beta$-acetoxy-mulin-9,12-diene (35) & $\mathrm{M}$ & SS & $\begin{array}{l}70 \mu \mathrm{gg} / \mathrm{dik}: \mathrm{ZI}= \\
15 \mathrm{~mm}\end{array}$ & $\begin{array}{l}\text { Penicillins/ } \\
\text { Streptomycin }\end{array}$ & [22] \\
\hline & \multirow{2}{*}{$\begin{array}{l}\text { S. aureus clinical } \\
\text { isolate MSSA }\end{array}$} & Mulin-12,14-dien-11-on-20-oic acid (12) & $\mathrm{M}$ & $\mathrm{N}$ & $\begin{array}{l}20 \mu \mathrm{g} / \text { disk: } \mathrm{ZI}= \\
8-12 \mathrm{~mm}\end{array}$ & \multirow{4}{*}{$\begin{array}{l}\text { Vancomycin } \\
30 \mu \mathrm{g} / \text { disk: } \\
\mathrm{ZI}=16-18 \mathrm{~mm}\end{array}$} & \multirow{4}{*}{ [40] } \\
\hline & & Mulin-12-ene-11,14-dion-20oic acid (13) & M & $\mathrm{N}$ & $\begin{array}{l}20 \mu \mathrm{g} / \text { disk: } \mathrm{ZI}= \\
8-12 \mathrm{~mm}\end{array}$ & & \\
\hline & \multirow{2}{*}{$\begin{array}{l}\text { S. aureus clinical } \\
\text { isolate MRSA }\end{array}$} & Mulin-12,14-dien-11-on-20-oic acid (12) & $\mathrm{M}$ & $\mathrm{N}$ & $\begin{array}{l}20 \mu \mathrm{g} / \text { disk: } \mathrm{ZI}= \\
8-12 \mathrm{~mm}\end{array}$ & & \\
\hline & & Mulin-12-ene-11,14-dion-20-oic acid (13) & M & $\mathrm{N}$ & $\begin{array}{l}20 \mu \mathrm{g} / \text { disk } \mathrm{ZI}= \\
8-12 \mathrm{~mm}\end{array}$ & & \\
\hline & $\begin{array}{l}\text { S. aureus } \\
\text { clinical isolate } \\
\text { MDR }\end{array}$ & $7 \beta$-acetoxy-mulin-9,12-diene (35) & $\mathrm{M}$ & SS & $\begin{array}{l}70 \mu \mathrm{g} / \text { disk: } \mathrm{ZI}= \\
13 \mathrm{~mm}\end{array}$ & $\begin{array}{l}\text { Penicillin/ } \\
\text { Streptomycin }\end{array}$ & [22] \\
\hline & \multirow{2}{*}{$\begin{array}{l}\text { Escherichia coli } \\
\text { (ATCC BAS-849) }\end{array}$} & Mulin-12,14-dien-11-on-20-oic acid (12) & $\mathrm{M}$ & $\mathrm{N}$ & $\begin{array}{l}20 \mu \mathrm{g} / \text { disk } \mathrm{ZI}= \\
8-12 \mathrm{~mm}\end{array}$ & \multirow{2}{*}{$\begin{array}{l}\text { Cefoxitin } \\
30 \mu \mathrm{\mu g} / \mathrm{dik}: \mathrm{ZI}= \\
16-18 \mathrm{~mm}\end{array}$} & \multirow{4}{*}{ [40] } \\
\hline & & Mulin-12-ene-11,14-dion-20-oic acid (13) & M & $\mathrm{N}$ & $\begin{array}{l}20 \mu \mathrm{g} / \text { disk: } \mathrm{ZI}= \\
8-12 \mathrm{~mm}\end{array}$ & & \\
\hline & \multirow{2}{*}{$\begin{array}{l}\text { Enterococcus faecium } \\
\text { clinical isolate } \\
\text { Vancomycin } \\
\text { resistant }\end{array}$} & Mulin-12,14-dien-11-on-20-oic acid (12) & M & $\mathrm{N}$ & $\begin{array}{l}20 \mu \mathrm{g} / \text { disk: } \mathrm{ZI}= \\
8-12 \mathrm{~mm}\end{array}$ & \multirow{2}{*}{$\begin{array}{l}\text { Bacitracin } 10 \\
\mu \mathrm{g} / \text { disk: ZI }= \\
16-18 \mathrm{~mm}\end{array}$} & \\
\hline & & Mulin-12-ene-11,14-dion-20-oic acid (13) & $\mathrm{M}$ & $\mathrm{N}$ & $\begin{array}{l}20 \mu \mathrm{g} / \text { disk: } \mathrm{ZI}= \\
8-12 \mathrm{~mm}\end{array}$ & & \\
\hline
\end{tabular}


Table 5. Cont.

\begin{tabular}{|c|c|c|c|c|c|c|c|}
\hline Activity & Study Model & Compound (Number) & Skeleton Type & Compound Origin & Biological Result & Positive Control & References \\
\hline \multirow{10}{*}{ Antiprotozoal } & \multirow{3}{*}{$\begin{array}{l}\text { Trichomonas } \\
\text { vaginalis } \\
\text { trophozoite as } \\
\text { (Ant-1 strain) } \\
\end{array}$} & 13ß-hydroxyazorellane (15) & A & $\mathrm{N}$ & $\mathrm{LD}_{50}=100 \mu \mathrm{M}$ & \multirow{3}{*}{$\begin{array}{l}\text { Metronidazole } \mathrm{LD}_{50} \\
=6.6 \mu \mathrm{M}\end{array}$} & \multirow{3}{*}{ [35] } \\
\hline & & $13 \alpha$-hydroxyazorellane (11) & A & $\mathrm{N}$ & $\mathrm{LD}_{50}=119 \mu \mathrm{M}$ & & \\
\hline & & Azorellanol (9) & A & $\mathrm{N}$ & $\mathrm{LD}_{50}=40.5 \mu \mathrm{M}$ & & \\
\hline & \multirow{2}{*}{$\begin{array}{l}\text { Toxoplasma gondii } \\
\text { trophozoites }\end{array}$} & $7 \beta$-deacetylazorellanol (16) & A & $\mathrm{N}$ & $\mathrm{LD}_{50}=54 \mu \mathrm{M}$ & \multirow{2}{*}{$\begin{array}{l}\text { Clindamycin } \mathrm{LD}_{50}= \\
84 \mu \mathrm{M}\end{array}$} & \multirow[b]{2}{*}{ [41] } \\
\hline & & Azorellanol (9) & A & $\mathrm{N}$ & $\mathrm{LD}_{50}=42 \mu \mathrm{M}$ & & \\
\hline & \multirow{2}{*}{$\begin{array}{l}\text { Trypanosoma cruzi } \\
\text { strains Tula-huen, } \\
\text { SPA-14 and CL } \\
\text { Brener clone }\end{array}$} & Mulin-11,3-dien-20-oic acid (6) & $\mathrm{M}$ & $\mathrm{N}$ & $\begin{array}{l}\% \mathrm{I}=92-98.4\left(\mathrm{IC}_{50}\right. \\
=41-87 \mu \mathrm{M}) \text { to } \\
10 \mu \mathrm{M}\end{array}$ & \multirow{2}{*}{ Gentian violet $1 \mu \mathrm{M}$} & \multirow{2}{*}{ [21] } \\
\hline & & Azorellanol (9) & A & $\mathrm{N}$ & $\begin{array}{l}\% \mathrm{I}=88.4-99 \mathrm{IC}_{50}= \\
20-84 \mu \mathrm{M} \text { to } 10 \mu \mathrm{M}\end{array}$ & & \\
\hline & \multirow{3}{*}{$\begin{array}{l}\text { Plasmodium berghei } \\
\text { (NK 65) }\end{array}$} & 20-hydroxymulin-11,13-dienyl acetate (21) & M & $\mathrm{N}$ & $\begin{array}{l}20 \mathrm{mg} / \mathrm{kg} / \text { day: } \% \mathrm{I} \\
=29 \text { to }\end{array}$ & \multirow{3}{*}{$\begin{array}{l}\text { Chloroquine } \\
5 \mathrm{mg} / \mathrm{kg} / \text { day IC } \mathrm{IC}_{50}= \\
2.5 \mathrm{mg} / \mathrm{kg} / \text { day }\end{array}$} & \multirow{3}{*}{ [29] } \\
\hline & & $13 \alpha, 14 \alpha$-dihydroxymulin-11-en-20-oic acid (18) & M & $\mathrm{N}$ & $\begin{array}{l}20 \mathrm{mg} / \mathrm{kg} / \mathrm{day}: \% \mathrm{I}= \\
42 \text { to }\end{array}$ & & \\
\hline & & 17-acetoxymulin-11,13-dien-20-oic acid (18) & M & $\mathrm{N}$ & $\begin{array}{l}20 \mathrm{mg} / \mathrm{kg} / \text { day:\% } \mathrm{I}= \\
60 \text { to }\end{array}$ & & \\
\hline \multirow{3}{*}{$\begin{array}{l}\text { Spermicidal/ } \\
\text { Spermatostatic }\end{array}$} & $\begin{array}{l}\text { Human sperm, } \\
\text { motile and } \\
\text { living cells }\end{array}$ & Azorellanone (17) & A & $\mathrm{N}$ & $\begin{array}{l}3 \mathrm{mM}: \% \mathrm{MC}=41 \% \\
3 \mathrm{mM}: \% \mathrm{LC}=57\end{array}$ & $\begin{array}{l}0.5 \% \text { ethyl acetate } \\
(\mathrm{vol} / \mathrm{vol})\end{array}$ & [68] \\
\hline & $\begin{array}{l}\text { Human sperm, } \\
\text { motile and } \\
\text { living cells }\end{array}$ & Mulinonic acid (5) & M & $\mathrm{N}$ & $\begin{array}{l}\% \mathrm{MC}=32 \% \\
\mathrm{LC}=84\end{array}$ & No data & \multirow{2}{*}{ [31] } \\
\hline & $\begin{array}{l}\text { Human sperm, } \\
\text { motile and } \\
\text { living cells }\end{array}$ & Azorellan-17,13-( $\beta$ )olide (azorellolide) (22) & A & $\mathrm{N}$ & $\begin{array}{l}\% \mathrm{MC}=34 \% \\
\mathrm{LC}=82\end{array}$ & No data & \\
\hline \multirow{5}{*}{ Cytotoxic } & \multirow{5}{*}{$\begin{array}{l}\text { Cancer cell line } \\
\text { MCF-7 (ATCC, } \\
\text { Mana-sas VA, UA), }\end{array}$} & Azorellanol (9) & A & $\mathrm{N}$ & $\mathrm{IC}_{50}=25.64 \mu \mathrm{M}$ & \multirow{5}{*}{$\begin{array}{l}\text { Doxorubicin } \mathrm{IC}_{50}= \\
5.52 \mu \mathrm{M}\end{array}$} & \multirow{5}{*}{ [28] } \\
\hline & & Mulin-11,13-dien-20-oic acid (6) & $\mathrm{M}$ & $\mathrm{N}$ & $\mathrm{IC}_{50}<100 \mu \mathrm{M}$ & & \\
\hline & & $7 \beta$-deacetylazorellanol (16) & A & $\mathrm{N}$ & $\mathrm{IC}_{50}<100 \mu \mathrm{M}$ & & \\
\hline & & 13ß-epiazorellanol (24) & A & $\mathrm{N}$ & $\mathrm{IC}_{50}<100 \mu \mathrm{M}$ & & \\
\hline & & $7 \beta$-acetoxy-mulin-9,12-diene (35) & $\mathrm{M}$ & $\mathrm{N}$ & $\mathrm{IC}_{50}<100 \mu \mathrm{M}$ & & \\
\hline
\end{tabular}


Table 5. Cont

\begin{tabular}{|c|c|c|c|c|c|c|c|}
\hline Activity & Study Model & Compound (Number) & Skeleton Type & Compound Origin & Biological Result & Positive Control & References \\
\hline \multirow{6}{*}{ Anti-inflammatory } & $\begin{array}{l}\text { In vivo assay, } \\
\text { arachidonic acid } \\
\text { model }\end{array}$ & Azorellanol (9) & A & $\mathrm{N}$ & $\begin{array}{l}6.3 \times 10^{-6} \mathrm{~mol} / \mathrm{ear}: \\
38.6 \% \\
\text { anti-inflammatory } \\
\text { effect }\end{array}$ & $\begin{array}{l}\text { Nimesulide } \\
3.2 \times 10^{-6} \mathrm{~mol} / \text { ear: } \\
48.8 \% \\
\text { anti-inflammatory } \\
\text { effect. } \\
\text { Indo-methacin } \\
1.4 \times 10^{-6} \mathrm{~mol} / \text { ear: } \\
28.0^{\circ} \\
\text { anti-inflammatory } \\
\text { effect }\end{array}$ & \multirow{3}{*}{ [42] } \\
\hline & \multirow{2}{*}{$\begin{array}{l}\text { In vivo assay, } \\
\text { 12-deoxy-phorbol } \\
13 \text { tetra-decanoate } \\
\text { model }\end{array}$} & Azorellanol (9) & A & $\mathrm{N}$ & $\begin{array}{l}15.0 \times 10^{-7} \mathrm{~mol} / \text { ear: } \\
70.8 \% \\
\text { anti-inflammatory } \\
\text { effect }\end{array}$ & \multirow{2}{*}{$\begin{array}{l}\text { Indomethacin } \\
1.4 \times 10^{-6} \mathrm{~mol} / \text { ear: } \\
81.8 \% \\
\text { anti-inflammatory } \\
\text { effect }\end{array}$} & \\
\hline & & $7 \beta$-deacetylazorellanol (16) & A & $\mathrm{N}$ & $\begin{array}{l}2.6 \times 10^{-6} \mathrm{~mol} / \mathrm{ear}: \\
79.0 \% \\
\text { anti-inflammatory } \\
\text { effect }\end{array}$ & & \\
\hline & \multirow{3}{*}{ anti-NF-kB } & Azorellanol (9) & A & $\mathrm{N}$ & Inhibition at $25 \mathrm{mg}$ & \multirow{3}{*}{ No data } & \multirow{3}{*}{ [44] } \\
\hline & & $7 \beta$-deacetylazorellanol (16) & A & $\mathrm{N}$ & Inhibition at $25 \mathrm{mg}$ & & \\
\hline & & 13 $\beta$-hydroxyazorellane (15) & A & $\mathrm{N}$ & Inhibition at $25 \mathrm{mg}$ & & \\
\hline \multirow{3}{*}{ Analgesic } & \multirow{3}{*}{$\begin{array}{l}\text { In vivo assay, } \\
\text { Acetic acid model }\end{array}$} & Azorellanol (9) & A & $\mathrm{N}$ & $\begin{array}{l}11.0 \times 10^{-5} \mathrm{~mol} / \mathrm{kg}: \\
50.7 \% \text { of analgesic } \\
\text { effect }\end{array}$ & \multirow{3}{*}{$\begin{array}{l}\text { Sodium naproxen } \\
4.9 \times 10^{-5} \mathrm{~mol} / \mathrm{kg}: \\
70.0 \% \text { of analgesic } \\
\text { effect }\end{array}$} & \multirow{3}{*}{ [42] } \\
\hline & & $7 \beta$-deacetylazorellanol (16) & A & $\mathrm{N}$ & $\begin{array}{l}5.7 \times 10^{-5} \mathrm{~mol} / \mathrm{kg}: \\
53.4 \% \text { of analgesic } \\
\text { effect }\end{array}$ & & \\
\hline & & Azorellanone (17) & A & $\mathrm{N}$ & $\begin{array}{l}10.0 \times 10^{-5} \mathrm{~mol} / \mathrm{kg}: \\
59.0 \% \text { of analgesic } \\
\text { effect }\end{array}$ & & \\
\hline \multirow{2}{*}{ Antihyperglycemic } & \multirow{2}{*}{$\begin{array}{l}\text { In vivo assay } \\
\text { Strepto-zotocin- } \\
\text { induced diabetic }\end{array}$} & Mulinolic acid (5) & $\mathrm{M}$ & $\mathrm{N}$ & $\begin{array}{l}180 \mathrm{mg} / \mathrm{mL}: 48 \% \\
\text { reduction of } \\
\text { glucose }\end{array}$ & \multirow{2}{*}{$\begin{array}{l}\text { Chlorpropamide } \\
5 \mathrm{mg} / \mathrm{mL}: 50.3 \% \\
\text { reduction of glucose }\end{array}$} & \multirow{2}{*}{ [23] } \\
\hline & & Azorellanol (9) & A & $\mathrm{N}$ & $\begin{array}{l}180 \mathrm{mg} / \mathrm{mL}: 49 \% \\
\text { reduction of } \\
\text { glucose }\end{array}$ & & \\
\hline
\end{tabular}


Table 5. Cont.

\begin{tabular}{|c|c|c|c|c|c|c|c|}
\hline Activity & Study Model & Compound (Number) & Skeleton Type & Compound Origin & Biological Result & Positive Control & References \\
\hline \multirow{12}{*}{ Antiulcer } & \multirow{8}{*}{$\begin{array}{l}\text { In vivo assay } \\
\text { HCl/EtOH-induced } \\
\text { injury model }\end{array}$} & Mulin-11,13-dien-18-acetoxy-16,20-dioic acid (31) & $\mathrm{M}$ & $\mathrm{N}$ & $\begin{array}{l}20 \mathrm{mg} / \mathrm{kg}: 73 \% \\
\text { reduction of } \\
\text { gastric injury }\end{array}$ & \multirow{8}{*}{$\begin{array}{l}\text { Lansoprazole } \\
20 \mathrm{mg} / \mathrm{kg}: 78 \% \\
\text { reduction of gastric } \\
\text { injury }\end{array}$} & \multirow{8}{*}{ [24] } \\
\hline & & Azorellanol (9) & A & $\mathrm{N}$ & $\begin{array}{l}20 \mathrm{mg} / \mathrm{kg}: 71 \% \\
\text { reduction of } \\
\text { gastric injury }\end{array}$ & & \\
\hline & & 13 $\beta$-hydroxyazorellane (15) & A & $\mathrm{N}$ & $\begin{array}{l}20 \mathrm{mg} / \mathrm{kg}: 69 \% \\
\text { reduction of } \\
\text { gastric injury }\end{array}$ & & \\
\hline & & 13 $\beta$-hydroxymulinane (28) & $\mathrm{M}$ & $\mathrm{N}$ & $\begin{array}{l}20 \mathrm{mg} / \mathrm{kg}: 59 \% \\
\text { reduction of } \\
\text { gastric injury }\end{array}$ & & \\
\hline & & Mulin-11,13-dien-20-ol (29) & M & $\mathrm{N}$ & $\begin{array}{l}20 \mathrm{mg} / \mathrm{kg}: 26 \% \\
\text { reduction of } \\
\text { gastric injury }\end{array}$ & & \\
\hline & & Mulin-11,13-dien-20-oic acid (6) & M & $\mathrm{N}$ & $\begin{array}{l}20 \mathrm{mg} / \mathrm{kg}: 39 \% \\
\text { reduction of } \\
\text { gastric injury }\end{array}$ & & \\
\hline & & $13 \alpha$-hydroxyazorellane (11) & A & $\mathrm{N}$ & $\begin{array}{l}20 \mathrm{mg} / \mathrm{kg}: 56 \% \\
\text { reduction of } \\
\text { gastric injury }\end{array}$ & & \\
\hline & & Mulinolic acid (5) & $\mathrm{M}$ & $\mathrm{N}$ & $\begin{array}{l}20 \mathrm{mg} / \mathrm{kg}: 55 \% \\
\text { reduction of } \\
\text { gastric injury }\end{array}$ & & \\
\hline & $\begin{array}{l}\text { In vivo assay } \\
\mathrm{HCl} / \mathrm{EtOH} \text {-induced } \\
\text { injury model }\end{array}$ & Mulin-11,13-dien-20-oic acid (6) & M & $\mathrm{N}$ & $\mathrm{ED}_{50}=55 \mathrm{mg} / \mathrm{kg}$ & $\begin{array}{l}\text { Lansoprazole } \\
20 \mathrm{mg} / \mathrm{kg}\end{array}$ & [36] \\
\hline & \multirow{3}{*}{$\begin{array}{l}\text { In vivo assay } \\
\text { HCl/EtOH-induced } \\
\text { injury model }\end{array}$} & 16-hydroxy-mulin-11,13-dien-20-oic acid (50) & M & SS & $\begin{array}{l}20 \mathrm{mg} / \mathrm{kg}: 59 \% \\
\text { reduction of } \\
\text { gastric injury }\end{array}$ & \multirow{3}{*}{$\begin{array}{l}\text { Lansoprazole } \\
20 \mathrm{mg} / \mathrm{kg}: 57 \% \\
\text { reduction of gastric } \\
\text { injury }\end{array}$} & \multirow{3}{*}{ [51] } \\
\hline & & $7 \alpha, 16$-dihydroxymulin-11,13-dien-20-oic acid (93) & M & SS & $\begin{array}{l}20 \mathrm{mg} / \mathrm{kg}: 69 \% \\
\text { reduction of } \\
\text { gastric injury }\end{array}$ & & \\
\hline & & 16-acetoxymulin-11,13-dien-20-oic acid (82) & M & SS & $\begin{array}{l}20 \mathrm{mg} / \mathrm{kg}: 43 \% \\
\text { reduction of } \\
\text { gastric injury }\end{array}$ & & \\
\hline
\end{tabular}


Table 5. Cont

\begin{tabular}{|c|c|c|c|c|c|c|c|}
\hline Activity & Study Model & Compound (Number) & Skeleton Type & Compound Origin & Biological Result & Positive Control & References \\
\hline & & $7 \alpha, 16$-diacetoxymulin-11,13-dien-20-oic acid (81) & $\mathrm{M}$ & SS & $\begin{array}{l}20 \mathrm{mg} / \mathrm{kg}: 48 \% \\
\text { reduction of } \\
\text { gastric injury }\end{array}$ & & \\
\hline & & $7 \alpha, 16$-dihydroxymulin-11,13-dien-20-oic acid methyl ester (85) & M & SS & $\begin{array}{l}20 \mathrm{mg} / \mathrm{kg}: 36 \% \\
\text { reduction of } \\
\text { gastric injury }\end{array}$ & & \\
\hline \multirow[b]{2}{*}{ Anti-Alzheimer. } & $\begin{array}{l}\text { Inhibition of the } \\
\text { enzyme } \\
\text { acetyl-choline-esteras }\end{array}$ & Mulinolic acid (5) & M & $\mathrm{N}$ & $\begin{array}{l}\mathrm{IC}_{50}=200 \mu \mathrm{g} / \mathrm{mL} \\
(630 \mu \mathrm{M})\end{array}$ & \multirow{2}{*}{$\begin{array}{l}\text { Galanthamine } \text { IC }_{50} \\
=1.1 \mu \mathrm{g} / \mathrm{mL}(3.0 \mu \mathrm{M})\end{array}$} & \multirow[b]{2}{*}{ [69] } \\
\hline & $\begin{array}{l}\text { Inhibition of the } \\
\text { enzyme } \\
\text { acetyl-choline-esteras }\end{array}$ & $\begin{array}{l}\text { Mulin-11,13-dien-20-oic acid (6) } \\
\text { se }\end{array}$ & $\mathrm{M}$ & $\mathrm{N}$ & $\begin{array}{l}\mathrm{IC}_{50}=180 \mu \mathrm{g} / \mathrm{mL} \\
(580 \mu \mathrm{M})\end{array}$ & & \\
\hline
\end{tabular}

N: Natural; SS: Semisynthetic. 


\subsection{Spermicidal/Spermatostatic Activity}

Mulinane and azorellane diterpenoids have been evaluated in terms of several parameters that characterize human sperm function, i.e., sperm motility and viability, sperm binding to the human zona pellucida, the progesterone-induced acrosome reaction, an increase in intracellular $\mathrm{Ca}^{2+}$ concentration, and protease activity in the search for a contraceptive method to inhibit, in a reversible and specific manner, the functions of the male gamete. Azorellanone (17), isolated from A. yareta, inhibited sperm motility in a concentration-dependent manner $(0.15-3 \mathrm{mM})$, while sperm viability was inhibited at $3 \mathrm{mM}$. Assays with 17 significantly inhibited sperm-zona binding, progesterone-induced acrosome reactions, and intracellular $\mathrm{Ca}^{2+}$ concentration. Additionally, $\mathbf{1 7}$ also affected protease activity and inhibited trypsin- and chymotrypsin-like activities. These results suggest that $\mathbf{1 7}$ may be a potential candidate as a contraceptive agent used in the manufacture of vaginal jellies or creams [68]. Other diterpenoids, such as mulinenic acid (4), mulinolic acid (5), and azorellan-17,13-( $\beta$ )olide (22), have been evaluated for their spermatostatic activity. Compounds (5) and (22) demonstrated significant spermatostatic properties [31].

\subsection{Antidiabetic}

Mulinolic acid (5) and azorellanol (9), both isolated from A. compacta, were evaluated for their antidiabetic activity in Streptozotocin-induced diabetic rats and both metabolites decreased glycemia at $180 \mathrm{mg} / \mathrm{mL}$, a similar value to that observed for Chlorpropamide used as positive control. Azorellanol (9) increased the insulin levels in serum; however, with (5) the levels of insulin remained unchanged; these results suggested that while (9) could be acting on the $\beta$-cells of pancreatic islets, (5) may be acting on glucose utilization or production in the liver [23].

\subsection{Antiulcer}

A number of azorellanes $(\mathbf{9}, \mathbf{1 1}$, and 15) and mulinanes $(\mathbf{1}, \mathbf{5}, \mathbf{6}, \mathbf{2 8}, \mathbf{2 9}, \mathbf{3 1}$, and 40) isolated from A. compacta exhibited gastroprotective activity in $\mathrm{HCl} / \mathrm{EtOH}$-induced gastric lesions in mice, at a dose of $20 \mathrm{mg} / \mathrm{kg}$. The best activity was caused by mulin-11,13-dien-18-acetoxy-16,20-dioic acid (31), azorellanol (9), and 13 $\beta$-hydroxyazorellane (15), with values (73-69\%) similar to those observed for the positive control Lansoprazole $(78-68 \%)$ at the same dose [24,26]. Similarly, mulin-11,13-dien-20-oic acid (6) isolated from $A$. trifurcata also demonstrated a gastroprotective effect $\left(\mathrm{ED}_{50}=55 \mathrm{mg} / \mathrm{kg}\right)$; the possible mode or gastroprotective action of $\mathbf{6}$ was evaluated in mice using a pre-treatment with various blockers such as Indomethacin (inhibitor of prostaglandin synthesis), N-ethylmaleimide (blocker of sulfhydryl compounds), N-nitro-L-arginine methyl ester (inhibitor of nitric oxide), and ruthenium red (vanilloid receptor antagonist). The results suggested that prostaglandins and sulfhydryl compounds are positively involved in the gastroprotective activity of this metabolite [36]. The gastroprotective effect of mulinanes has led to the exploration of different chemical modifications in the diterpenoid structure to improve activity; the evaluation of a number of semisynthetic (81-86) and biotransformed $(50,93)$ mulinane derivatives have allowed the identification of $7 \alpha, 16$-dihydroxymulin-11,13-dien-20-oic acid $(\mathbf{9 3}, 69 \%)$ and 16-hydroxy-mulin-11,13-dien-20-oic acid (50,59\%) as the most active derivatives when tested at a dose of $20 \mathrm{mg} / \mathrm{kg}$, both showing a better gastroprotective effect than Lansoprazole $(57 \%)$ at the same dose. Interestingly, an apparent relationship between the polarity of the derivatives and their gastroprotective activity was established, with the decrease in polarity causing the loss of activity [51].

\subsection{Anti-Inflammatory}

A search for bioactive metabolites with anti-inflammatory and analgesic properties produced by A. compacta, A. yareta, and L. acaulis resulted in the identification of azorellanol (9), azorellanone (17), and $7 \beta$-deacetylazorellanol (16); azorellanol (9) showed anti-inflammatory activity when tested on arachidonic acid (AA) and 12-deoxyphorbol-13-Tetradecanoate (TPA)-induced edemas. The fact that (9) 
showed a higher activity on the TPA than in the AA-induced edema assays (dose: $15 \times 10-7 \mathrm{~mol} / \mathrm{ear}$ ) and that the dermal anti-inflammatory activity was of $70.8 \%$, suggests that the mechanism of action of (9) could involve the inhibition of cyclo-oxygenase activity. Alternatively, (17) showed the strongest analgesic activity when the three metabolites were tested in the acetic acid-induced abdominal constriction response in mice model (59\% of analgesic effect, dose: $10 \times 10^{-5} \mathrm{~mol} / \mathrm{kg}$ ) [42]. Additional studies on the anti-inflammatory properties of azorellanol (9) showed its having an effect $(25 \mathrm{mg} / \mathrm{mL})$ on the inhibition of the transcription factor Nuclear Factor-kappa Beta (NF-kB), one of the key regulators of the genes involved in the immune/inflammatory response [70], in the NF-kB-dependent luciferase gene reporter assay. Finally, 7 7 -deacetylazorellanol (16) also demonstrated anti-NF- $\mathrm{kB}$ activity [44].

\subsection{Cytotoxic}

Other activities reported for mulinanes and azorellanes include cytotoxic activity on human breast adenocarcinoma cells (MCF-7); mulin-11,13-dien-20-oic acid (6), azorellanol (9), $7 \beta$-deacetylazorellanol (16), 13 $\beta$-epiazorellanol (24), and 7 $\beta$-acetoxy-mulin-9,12-diene (35) displayed good cytotoxic activity (less than $50 \%$ cell viability at $100 \mu \mathrm{M}$ ), with azorellanol (9) being the most active ( IC $_{50}=25.64 \mu \mathrm{M}$ ). The results obtained in this investigation suggested that the beta acetate group at C-7 was required to increase the cytotoxic effect. Additionally, the alpha position of the $\mathrm{OH}$ group at position $\mathrm{C}-13$ in the same skeleton further increased the cytotoxic effect when comparing the cytotoxic effect of the epimers $16(\mathrm{OH}-13$ in beta position) and 9 (OH-13 in alpha position) [28].

\subsection{Anti-Alzheimer}

Mulinanes have also been evaluated in the inhibition of acetylcholinesterase (AChE). Inhibition of AChE serves as a strategy for the treatment of Alzheimer disease (AD), senile dementia, ataxia, myasthenia gravis, and Parkinson disease, and it has been considered as a potential therapeutic approach to AD. Mulinolic acid (5) and mulin-11,13-dien-20-oic acid (6), both isolated from A. trifurcata, have shown moderate inhibitory activity toward the enzyme $\mathrm{AChE}$ in a colorimetric assay with $\mathrm{IC}_{50}$ of 200 and $180 \mu \mathrm{g} / \mathrm{mL}$, respectively [69].

\section{Conclusions}

This is a report that systematically describes the biosynthesis, occurrence, isolation, structures, and biological activities of mulinane and azorellane diterpenoids. In summary, a total of 95 of these compounds has been reported since 1990. Thirty-seven mulinanes and 12 azorellanes have been isolated from species of Azorella, Laretia, and Mulinum genera. Synthesis, chemical modifications, and biotransformation by Mucor plumbeus and M. circinelloides have produced 4 synthetics and 44 mulinane derivatives. Even though these diterpenoids have been extensively studied because of their biological properties such as antimicrobial, antiprotozoal, spermicidal, gastroprotective, anti-inflammatory, antidiabetic, cytotoxic, and anti-Alzheimer, a large number of mulinanes and azorellanes have shown important anti-M. tuberculosis and gastroprotective activities. The antimycobacterial activity of the semisynthetic $n$-propyl (74) and $n$-butyl (75) esters of isomulinic acid (2) and of $13 \alpha$-hydroxy-mulin-11-en-20-oic-acid n-propyl ester (62) suggest that an increase in the size/length of the substituent could increase the potency of mulinane derivatives.

Traditional uses of species of Azorella, Laretia, and Mulinum for stomach ulcers led to the evaluation of the diterpenoid compounds isolated from these plants in gastroprotective model. Mulin-11,13-dien-18-acetoxy-16,20-dioic acid (31), azorellanol (9), and 13 $\beta$-hydroxyazorellane (15) demonstrated best gastroprotective effect. The biotransformation and chemical modification of mulin-11,13-dien-20-oic acid (6) led to the improvement of its gastroprotective effect.

Currently, only a small amount of research has been involved in the analysis of the structure-activity relationship in mulinanes and azorellanes. Similarly, studies on the target genes, target proteins, and signaling pathways involved in the mechanisms of action of mulinane and azorellane diterpenoids are limited; these studies are necessary in order have a mulinane or azorellane become a potential 
pharmaceutical. With this review we intended to make a significant contribution to the current knowledge about these interesting diterpenoids, as well as to encourage their continuing study.

Author Contributions: Conceptualization, G.M.M.-S. and A.d.J.D.-B.; investigation, G.M.M.-S., A.d.J.D.-B., and A.H.U.-C.; resources, G.M.M.-S., L.M.P.-R., J.B., and L.A.L.; writing-original draft preparation, G.M.M.-S., A.d.J.D.-B., and A.H.U.-C.; writing-review and editing, L.M.P.-R., J.B., and L.A.L.; and supervision, G.M.M.-S. All authors have read and agreed to the published version of the manuscript.

Funding: This study was supported by CONACYT-México grant \#PDCPN2013/213558 (GMMS) and Universidad de Antofagasta Centro de Costos de Rectoría \# 1001 (JBR). From CONACYT-México AJD-B received Bachelor-degree fellowship \#22545.

Acknowledgments: The authors are grateful to Maggie Brunner, M.A., for the English-language review of this article.

Conflicts of Interest: The authors declare no conflict of interest.

\section{References}

1. Sen, T.; Samanta, S.K. Medicinal plants, human health and biodiversity: A broad review. Adv. Biochem. Engin./Biotechnol. 2014, 123, 127-141.

2. Solecki, R. Shanidar IV, a Neanderthal flower burial in northern Iraq. Science 1975, 190, 880-881. [CrossRef]

3. Cragg, G.M.; Newman, D.J. Natural products: A continuing source of novel drug leads. Biochim. Biophys. Acta 2013, 1830, 3670-3695. [CrossRef] [PubMed]

4. World Health Organization. The World Medicines Situation 2011-Traditional Medicines: Global Situation, Issues and Challenges. Available online: http://digicollection.org/hss/documents/s180 (accessed on 4 May 2012).

5. Batiha, G.E.S.; Alkazmi, L.M.; Wasef, L.G.; Beshbishy, A.M.; Nadwa, E.H.; Rashwan, E.K. Syzygium aromaticum L. (Myrtaceae): Traditional uses, bioactive chemical constituents, pharmacological and toxicological activities. Biomolecules 2020, 10, 202. [CrossRef] [PubMed]

6. Pye, C.R.; Bertin, M.J.; Lokey, R.S.; Gerwick, W.H.; Linington, R.G. Retrospective analysis of natural products provides insights for future discovery trends. Proc. Natl. Acad. Sci. USA 2017, 114, 5601-5606. [CrossRef]

7. Nwokeji, P.A.; Enodiana, I.O.; Raymond, E.S.; Osasere, O.-I.; Abiola, A.H. The Chemistry of natural product: Plant secondary metabolites. Int. J. Technol. Enhanc. Merg. Eng. Res. 2016, 4, 1-9.

8. Newman, D.J.; Cragg, G.M. Natural products as sources of new drugs from 1981 to 2014. J. Nat. Prod. 2016, 79, 629-661. [CrossRef]

9. Li, G.; Low, H.X. Strategies to diversify natural products for drug discovery. Med. Res. Rev. 2017, 38, 1255-1294. [CrossRef]

10. Bórquez, J.; Ardiles, A.; Loyola, L.A.; Peña-Rodriguez, L.M.; Molina-salinas, G.M.; Vallejos, J.; Collado, I.G.; Simirgiotis, M.J. Further mulinane and azorellane diterpenoids isolated from Mulinum crassifolium and Azorella compacta. Molecules 2014, 19, 3898-3908. [CrossRef]

11. Marcos, I.S.; Moro, R.F.; Gil-Mesón, A.; Díez, D. 7-6-5 Tricarbocyclic diterpenes: Valparanes, mulinanes, cyathanes, homoverrucosanes, and related ones. In Studies in Natural Products Chemistry; Atta-ur-Rahman, Ed.; Elsevier: Amsterdam, The Netherlands, 2016; Volume 48, pp. 137-207.

12. Reber, K.P.; Xu, J.; Guerrero, C.A. Synthesis of mulinane diterpenoids. J. Org. Chem. 2015, 80, $2397-2406$. [CrossRef]

13. Simoneit, B.R.T.; Oros, D.R.; Jaffé, R.; Didyk-Peña, A.; Areche, C.; Sepúlveda, B.; Didyk, B.M. Mulinane and azorellane diterpenoid biomarkers by GC-MS from a representative Apiaceae (Umbelliferae) species of the Andes. Molecules 2019, 24, 684. [CrossRef] [PubMed]

14. Caceres De Baldarrago, F.; Poma, I.; Spadaro, V. Evaluación etnobotanica de la Yareta (Azorella compacta) en Arequipa (Perú) y sus posibles aplicaciones. Quad. Bot. Amb. Appl. 2012, 23, 15-30.

15. Wickens, G.E. Llareta (Azorella compacta, Umbelliferae): A Review. Econ. Bot. 1995, 49, 207-212. [CrossRef]

16. Areche, C.; Fernandez-Burgos, R.; Cano de Terrones, T.; Simirgiotis, M.; García-Beltran, O.; Borquez, J.; Sepulveda, B. Mulinum crassifolium Phil; two new mulinanes, gastroprotective activity and metabolomic analysis by UHPLC-orbitrap mass spectrometry. Molecules 2019, 24, 1673. [CrossRef] [PubMed] 
17. Loyola, L.A.; Morales, G.; Rodríguez, B.; Jiménez-Barbero, J.; De la Torre, M.C.; Perales, A.; Torres, M.R. Mulinic and isomulinic acids. Rearranged diterpenes with a new carbon skeleton from Mulinum crassifolium. Tetrahedron 1990, 46, 5413-5420. [CrossRef]

18. Nicolas, A.N.; Plunkett, G.M. Untangling generic limits in Azorella, Laretia, and Mulinum (Apiaceae: Azorelloideae): Insights from phylogenetics and biogeography. Taxon 2012, 61, 826-840. [CrossRef]

19. Luteyn, J.L. Paramos: A Checklist of Plant Diversity, Geographical Distribution, and Botanical Literature, 1st ed.; Luteyn, J., Ed.; The New York Botanical Garden Press: New York, NY, USA, 1999; pp. 1-258.

20. Loyola, L.A.; Borquez, J.; Morales, G. Azorellanol: A diterpenoid with a new carbon skeleton from Azorella compacta. Tetrahedron 1998, 54, 15533-15540. [CrossRef]

21. Araya, J.E.; Neira, I.; Da Silva, S.; Mortara, R.A.; Manque, P.; Cordero, E.; Sagua, H.; Loyola, A.; Bórquez, J.; Morales, G.; et al. Diterpenoids from Azorella compacta (Umbelliferae) active on Trypanosoma cruzi. Mem. Inst. Oswaldo Cruz 2003, 98, 413-418. [CrossRef]

22. Donoso, V.; Bacho, M.; Nuñez, S.; Rovirosa, J.; San-Martín, A.; Leiva, S. Antimicrobial diterpenes from Azorella species against gram-positive bacteria. Nat. prod. Commun. 2015, 10, 1915-1916. [CrossRef]

23. Fuentes, N.L.; Sagua, H.; Morales, G.; Borquez, J.; San-Martin, A.; Soto, J.; Loyola, L.A. Experimental antihyperglycemic effect of diterpenoids of llareta Azorella compacta (umbelliferae) Phil in rats. Phytother. Res. 2005, 19, 713-716. [CrossRef]

24. Areche, C.; Rojas-Alvarez, F.; Campos-Briones, C.; Lima, C.; Pérez, E.G.; Sepúlveda, B. Further mulinane diterpenoids from Azorella compacta. J. Pharm. Pharmacol. 2013, 65, 1231-1238. [CrossRef] [PubMed]

25. Loyola, L.A.; Borquez, J.B.; Morales, G.; San-Martin, A. Mulinol, a diterpenoid from Azorella compacta. Phytochemistry 1997, 45, 1465-1467. [CrossRef]

26. Salgado, F.; Areche, C.; Sepúlveda, B.; Simirgiotis, M.J.; Cáceres, F.; Quispe, C.; Quispe, L.; Cano, T. A new mulinane diterpenoid from the cushion shrub Azorella compacta growing in Perú. Pharmacogn. Mag. 2014, 10, S543-S548. [PubMed]

27. Loyola, L.A.; Morales, G.; de la Torre, M.C.; Pedreros, S.; Rodriguez, B. 17-acetoxymulinic acid, a rearranged diterpenoid from Mulinum crassifolim. Phytochemistry 1990, 29, 3950-3951. [CrossRef]

28. Bórquez, J.; López-Bartolucci, N.; Echiburú-Chau, C.; Winterhalter, P.; Vallejos, J.; Jerz, G.; Simirgiotis, M.J. Isolation of cytotoxic diterpenoids from the Chilean medicinal plant Azorella compacta Phil from the Atacama Desert by high-speed counter-current chromatography. J. Sci. Food. Agric. 2016, 96, 2832-2838. [CrossRef] [PubMed]

29. Loyola, L.A.; Bórquez, J.; Morales, G.; San-Martín, A.; Darias, J.; Flores, N.; Giménez, A. Mulinane-type diterpenoids from Azorella compacta display antiplasmodial activity. Phytochemistry 2004, 65, 1931-1935. [CrossRef]

30. Loyola, L.A.; Morales, G. Mulinenic acid, a rearranged diterpenoid from Mulinum crassifolium. J. Nat. Prod. 1991, 54, 1404-1408. [CrossRef]

31. Chiaramello, A.I.; Yunes, R.; Rossomando, P.C.; Cifuentes, D.A. In vitro spermatostatic activity of mulinaneand azorellane-type diterpenes on human spermatozoa. Lat. Am. J. Pharm. 2011, 30, 1325-1329.

32. Chiaramello, A.I.; Ardanaz, C.E.; García, E.E.; Rossomando, P.C. Mulinane-type diterpenoids from Mulinum spinosum. Phytochemistry 2003, 63, 883-886. [CrossRef]

33. Loyola, L.A.; Borquez, J.; Morales, G.; San-Martin, A. Diterpenoids from Azorella compacta. Phytochemistry 1997, 44, 649-651. [CrossRef]

34. Loyola, L.A.; Borquez, J.; Morales, G.; San-Martin, A. Mulinolic acid, a diterpenoid from Mulinum crassifolium. Phytochemistry 1996, 43, 165-168. [CrossRef]

35. Loyola, L.A.; Bórquez, J.; Morales, G.; Araya, J.; González, J.; Neira, I.; Sagua, H.; San-Martín, A. Diterpenoids from Azorella yareta and their trichomonicidal activities. Phytochemistry 2001, 56, 177-180. [CrossRef]

36. Areche, C.; Sepulveda, B.; San-Martin, A.; Garcia-Beltrán, O.; Simirgiotis, M.; Cañete, A. An unusual mulinane diterpenoid from the Chilean plant Azorella trifurcata (Gaertn) Pers. Org. Biomol. Chem. 2014, 12, 6406-6413. [CrossRef] [PubMed]

37. Nicoletti, M.; Di Fabio, A.; D’Andrea, A.; Salvatore, G.; Van Baren, C.; Coussio, J.D. Diterpenoid acids from Mulinum spinosum. Phytochemistry 1996, 43, 1065-1067. [CrossRef]

38. Loyola, L.A.; Bórquez, J.; Morales, G.; San-Martín, A. Mulinane-type diterpenoids from Laretia acaulis. Phytochemistry 2000, 53, 961-963. [CrossRef] 
39. Areche, C.; Vaca, I.; Loyola, L.A.; Borquez, J.; Rovirosa, J.; San-Martín, A. Diterpenoids from Azorella madreporica and their antibacterial activity. Planta Med. 2010, 76, 1749-1751. [CrossRef]

40. Wächter, G.A.; Matooq, G.; Hoffmann, J.J.; Maiese, W.M.; Singh, M.P.; Montenegro, G.; Timmennann, B.N. Antibacterial diterpenoid acids from Azorella compacta. J. Nat. Prod. 1999, 62, 1319-1321. [CrossRef]

41. Loyola, L.A.; Borquez, J.; Morales, G.l.; Araya, J.; Gonzalez, J.; Neira, I.; Sagua, H.; San-Martín, A. Azorellane diterpenoids from Laretia acaulis, and its toxoplasmacidal activity. Bol. Soc. Chil. Quím. 2001, 46, 9-13. [CrossRef]

42. Delporte, C.; Backhouse, N.; Salinas, P.; San-Martín, A.; Bórquez, J.; Loyola, A. Pharmaco-toxicological study of diterpenoids. Bioorg. Med. Chem. 2003, 11, 1187-1190. [CrossRef]

43. Lima, B.; Sanchez, M.; Agüero, M.B.; Tapia, A.; Palermo, J.A.; Feresin, G.E. Antibacterial activity of extracts and compounds isolated from the Andean medicinal plant Azorella cryptantha (Clos) Reiche, Apiaceae. Ind. Crops Prod. 2015, 64, 152-157. [CrossRef]

44. Borquez, J.; Loyola, L.A.; Morales, G.; San-Martín, A.; Roldan, R.; Marquez, N.; Muñoz, E. Azorellane diterpenoids from Laretia acaulis inhibit Nuclear Factor-kappa B activity. Phytother. Res. 2007, 1086, 1082-1086. [CrossRef] [PubMed]

45. Loyola, L.A.; Borquez, J.; Morales, G.; San-Martín, A. 11,12-epoxy-mulin-13-en-20-oic acid, a diterpenoid from Azorella compacta. Phytochemistry 1998, 49, 1091-1093. [CrossRef]

46. Wächter, G.A.; Franzblau, S.G.; Montenegro, G.; Suarez, E.; Fortunato, R.H.; Saavedra, E.; Timmermann, B.N. A new antitubercular mulinane diterpenoid from Azorella madreporica Clos. J. Nat. Prod. 1998, 61, 965-968. [CrossRef] [PubMed]

47. Bórquez, J.; Molina-Salinas, G.M.; Loyola, L.A.; San-Martin, A.; Peña-Rodríguez, L.M.; Said-Fernández, S. A new azorellane diterpenoid from Azorella madreporica. Nat. Prod. Res. 2011, 25, 653-657. [CrossRef]

48. Colloca, C.B.; Pappano, D.B.; Bustos, D.A.; Sosa, V.E.; Baggio, R.F.; Garland, M.T.; Gil, R.R. Azorellane diterpenes from Azorella cryptantha. Phytochemistry 2004, 65, 2085-2089. [CrossRef]

49. Colloca, C.B.; Bustos, D.A.; Espinar, L.A.; Sosa, V.E. Terpenoid from Azorella Cryptantha. Nat. Prod. Indian J. 2014, 10, 8-11.

50. Astudillo, L.; Gutiérrez, M.; Quesada, L.; San-Martín, A.; Espinoza, L.; Peñailillo, P. New Diterpenes from Azorella spinosa. Nat. Prod. Commun. 2014, 9, 9-12. [CrossRef]

51. Sepúlveda, B.; Quispe, C.; Simirgiotis, M.; García-Beltrán, O.; Areche, C. Gastroprotective effects of new diterpenoid derivatives from Azorella cuatrecasasii Mathias \& Constance obtained using a $\beta$-cyclodextrin complex with microbial and chemical transformations. Bioorg. Med. Chem. Lett. 2016, 26, 3220-3222.

52. San-Martín, A.; Bacho, M.; Nuñez, S.; Rovirosa, J.; Soler, A.; Blanc, V.; Leon, R.; Olea, A.F. A novel normulinane isolated from Azorella compacta and assessment of its antibacterial activity. J. Chil. Chem. Soc. 2018, 63, 3-6. [CrossRef]

53. Liu, Y.-T.; Li, L.-P.; Xie, J.-H.; Zhou, Q.-L. Divergent asymmetric total synthesis of mulinane diterpenoids. Angew. Chem. Int. Ed. 2017, 56, 12708-12711. [CrossRef]

54. Molina-Salinas, G.M.; Bórquez, J.; Ardiles, A.; Said-Fernández, S.; Loyola, L.A.; Yam-Puc, A.; Becerril-Montes, P.; Escalante-Erosa, F.; San-Martin, A.; González-Collado, I.; et al. Bioactive metabolites from the Andean flora. Antituberculosis activity of natural and semisynthetic azorellane and mulinane diterpenoids. Phytochem. Rev. 2010, 9, 271-278. [CrossRef]

55. Herrera-Canché, S.G.; Sánchez-González, M.; Loyola, L.A.; Bórquez, J.; García-Sosa, K.; Peña-Rodríguez, L.M. Biotransformation of a mulinane diterpenoid by Aspergillus alliaceus and Mucor circinelloides. Biocatal. Biotransfor. 2019, 38, 1-6. [CrossRef]

56. Areche, C.; Loyola, L.A.; Borquez, J.; Rovirosa, J.; San-Martin, A. Microbial transformation of the diterpene mulin-11, 13-dien-20-oic acid by Mucor plumbeus. Magn. Reson. Chem. 2008, 46, 765-768. [CrossRef] [PubMed]

57. Molina-Salinas, G.M.; Bórquez, J.; Ardiles, A.; Said-Fernández, S.; Loyola, L.A.; San-Martín, A.; González-Collado, I.; Peña-Rodríguez, L.M. Antituberculosis activity of natural and semisynthetic azorellane and mulinane diterpenoids. Fitoterapia 2010, 81, 50-54. [CrossRef]

58. Nuñez, S.; San-Martin, A.; Corsini, G. Antimicrobial activities of diterpenoids and semisynthetic derivatives from Azorella compacta. J. Chil. Chem. Soc. 2018, 63, 4200-4204. [CrossRef] 
59. Molina-Salinas, G.M.; Bórquez, J.; Said-Fernández, S.; Loyola, L.A.; Yam-Puc, A.; Becerril-Montes, P.; Escalante-Erosa, F.; Peña-Rodríguez, L.M. Antituberculosis activity of alkylated mulinane diterpenoids. Fitoterapia 2010, 81, 219-222. [CrossRef]

60. Brito, I.; Borquez, J.; Muñoz, R.; Cárdenas, A. Crystal and molecular structure of $14 \alpha$-acetoxy-13 $\alpha-$ hydroxymulin-11-en-20-oic acid monohydrate. J. Chil. Chem. Soc. 2018, 1, 17-19.

61. Thomford, N.E.; Senthebane, D.A.; Rowe, A.; Munro, D.; Seele, P.; Maroyi, A.; Dzobo, K. Natural products for drug discovery in the $21^{\text {st }}$ century: Innovations for novel drug discovery. Int. J. Mol. Sci. 2018, 19, 1578. [CrossRef]

62. Zinner, S.H. The search for new antimicrobials: Why we need new options. Expert Rev. Anti Infect. Ther. 2005, 3, 907-913. [CrossRef]

63. Yao, H.; Liu, J.; Xu, S.; Zhu, Z.; Xu, J. The structural modification of natural products for novel drug discovery. Expert Opin. Drug Discov. 2016, 12, 121-140. [CrossRef]

64. Dzul-Beh, A.d.J.; García-Sosa, K.; Uc-Cachón, A.H.; Bórquez, J.; Loyola, L.A.; Barrios-García, H.B.; Peña-Rodríguez, L.M.; Molina-Salinas, G.M. In vitro growth inhibition and bactericidal activity of spathulenol against drug-resistant clinical isolates of Mycobacterium tuberculosis. Rev. Bras. Farmacogn. 2019, 29, 798-800. [CrossRef]

65. Lee, S.M.; Kim, M.S.; Hayat, F.; Shin, D. Recent advances in the discovery of novel antiprotozoal agents. Molecules 2019, 24, 3886. [CrossRef] [PubMed]

66. Mahmoud, A.B.; Mäser, P.; Kaiser, M.; Hamburger, M.; Khalid, S. Mining sudanese medicinal plants for antiprotozoal agents. Front. Pharmacol. 2020, 11, 1-14. [CrossRef] [PubMed]

67. Moreno-Herrera, A.; Cortez-Maya, S.; Bocanegra-Garcia, V.; Banik, B.K.; Rivera, G. Recent advances in the development of broad-spectrum antiprotozoal agents. Curr. Med. Chem. 2020. [CrossRef]

68. Morales, P.; Kong, M.; Pizarro, E.; Pasten, C.; Morales, G.; Borquez, J.; Loyola, L.A. Effect of azorellanone, a diterpene from Azorella yareta Hauman, on human sperm physiology. J. Androl. 2003, 24, 364-370. [CrossRef]

69. Areche, C.; Cejas, P.; Thomas, P.; San-Martin, A.; Astudillo, L.; Gutiérrez, M.; Loyola, L.A. Triterpenoids from Azorella trifurcata (Gaertn.) Pers and their effect against the enzyme acetylcholinesterase. Quim. Nova 2009, 32, 2023-2025. [CrossRef]

70. Liu, T.; Zhang, L.; Joo, D.; Sun, S.C. NF-к B signaling in inflammation. Signal Transduct Target. Ther. 2017, 2, e17023. [CrossRef] 